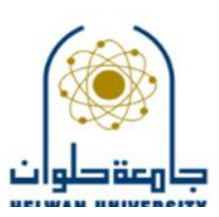

المعهد القومى للملكية الفكرية

The National Institute of Intellectual Property

Helwan University, Egypt

المجلة العلمية للملكية الفكرية وإدارة الابتكار

دورية نصف سنوية محكمة يصلدرها

المعهد القومي للملكية الفكرية

جامعة حلوان

العلدد الثالث

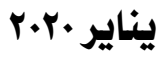




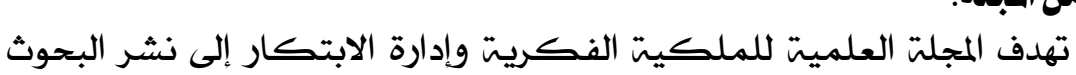

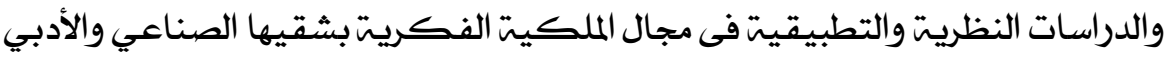

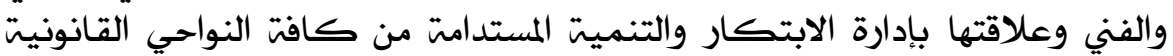

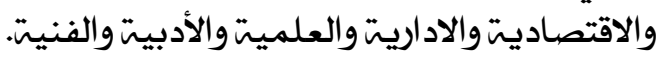

ضوابط عامة:

تعبر كافت الدراسات والبحوث والمقالات عن رأى مؤلفيها ويأتي ترتيبها بالمجلة وفقا لإعتبارات فنيت لا علاقت لها بالقيمت العلميت لألى والى منها. تنشر المقالات غير المحكمة (أوراق العمل) فى زاويت خاصتّات في المجلتة.

تنشر المجلت مراجعات وعروض الكتب الجديدة والدوريكات.

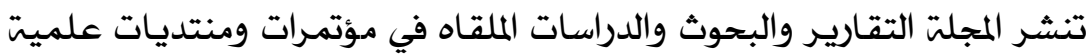

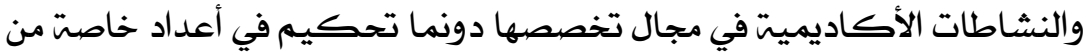
المجلة. يمكن الاقتباس من بعض مواد المجلمت بشرط الاشارة إلى المصدر.

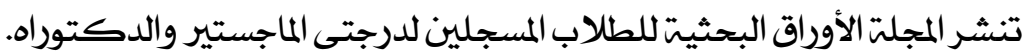

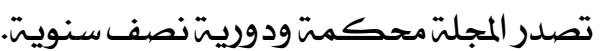

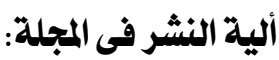

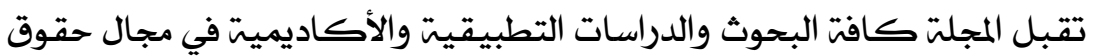

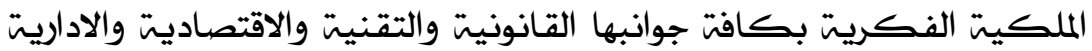

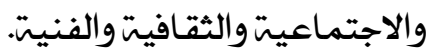

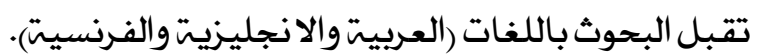

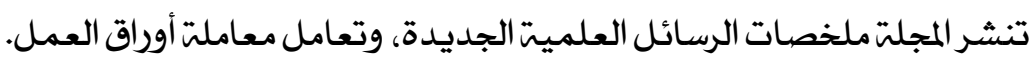

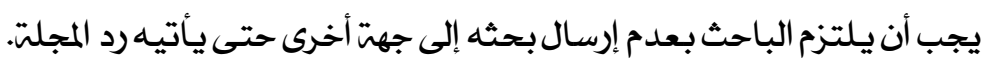

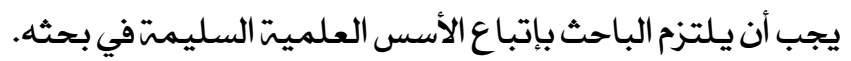

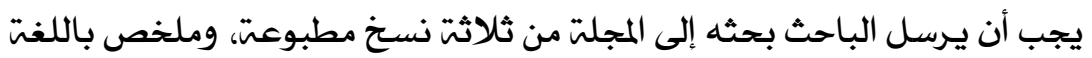

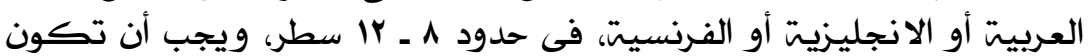

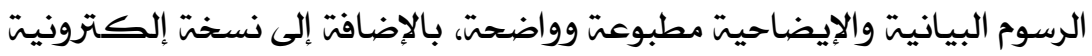
عoft Copy

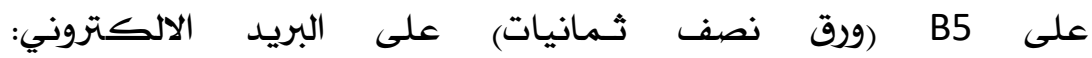
ymgad@niip.edi.eg ترسل البحوث إلى محكمين متخصصين وتحكم بسريت تامت.

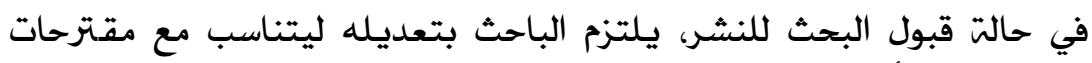
المحكمين، وأسلوب النشر بالمجلتة. 


\begin{tabular}{|c|c|}
\hline \multicolumn{2}{|c|}{ مجلس إدارة تحرير المجلة } \\
\hline 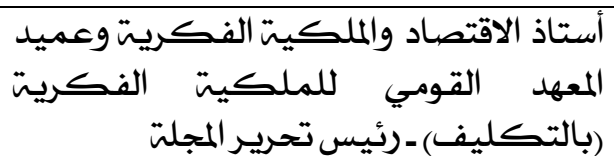 & أ.د. ياسر محمد جاد اللَه محمود \\
\hline 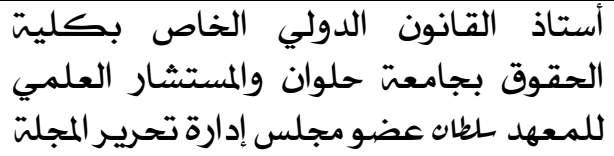 & أ.د. أحمد عبد الكريم سلامة \\
\hline سكرتير تحرير المجلة & أ.د. وكيل المعهد للدراسات العليا والبحوث \\
\hline 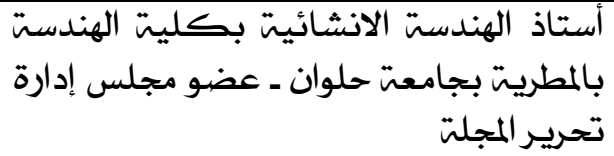 & أ.د. جلال عبد الحميد عبد اللاه \\
\hline 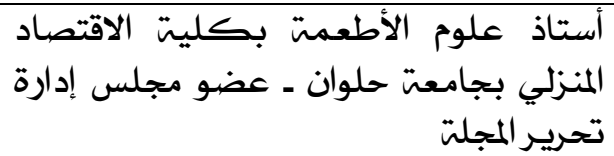 & أ.د. هناي محمد الحسيني \\
\hline 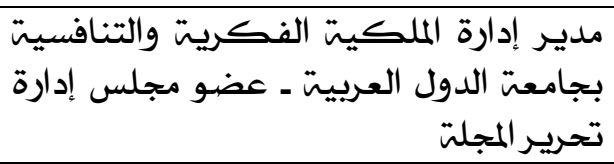 & أ.د. وزير مفوض/ مها بخيت محمد زكي \\
\hline 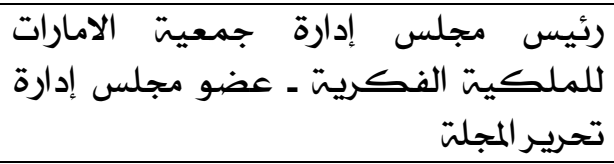 & اللواء أ.د. عبد القدوس عبد الرزاق العبيدلي \\
\hline 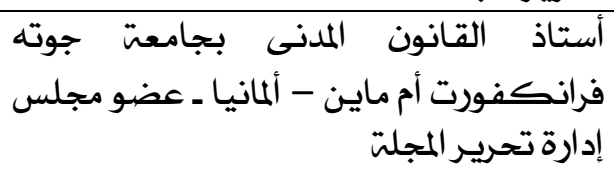 & Prof Dr. Alexander Peukert \\
\hline 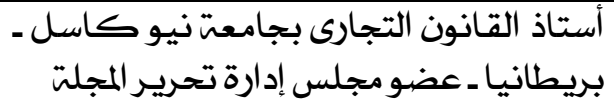 & Prof Dr. Andrew Griffiths \\
\hline
\end{tabular}

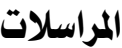

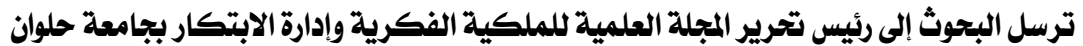

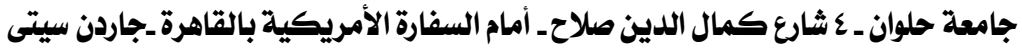

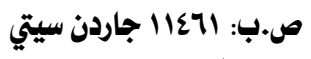

ت:

http://www.helwan.edu.eg/niip/

ymgad@niip.edu.eg 
دور الاتفاقيات الدولية في حماية هيئات البث الاذاعي في البيئة الرقمية

آلائ محمد محمود عمار 


\section{دور الاتفاقيات الدولية في حماية هيئات البث الاذاعي في البيئة الرقمية آلائ محمد محمود عمار}

مقدمة

تشكل البيئة الرقمية لما تتيحه من وسائل عديدة في تسهيل استتساخ الإخاخ

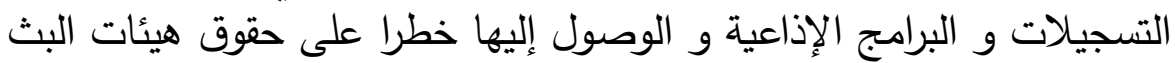

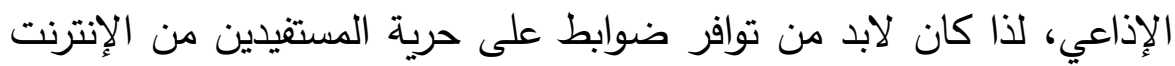

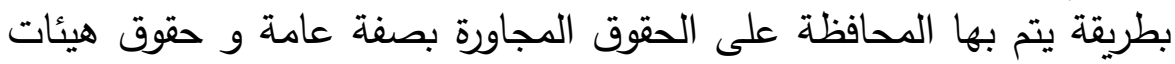

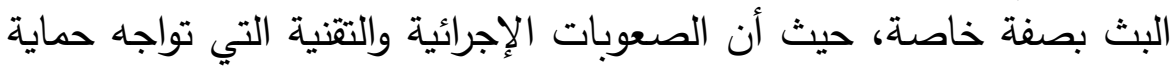

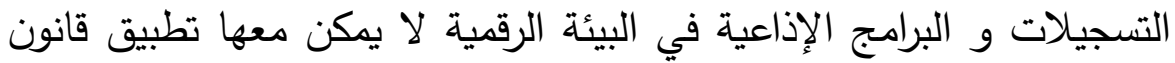

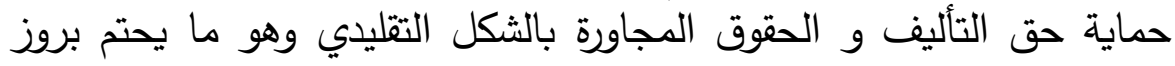

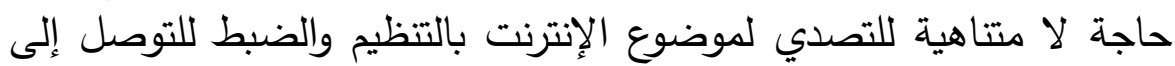

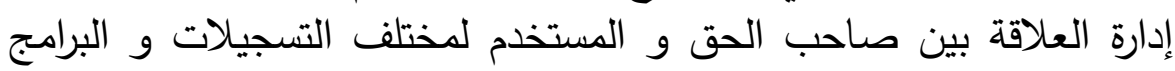
الإذاعية على شبكة الإنترنت.

و في هذا البحث سنتناول حقوق هيئات البث الإذاعي باعتبارها أحد

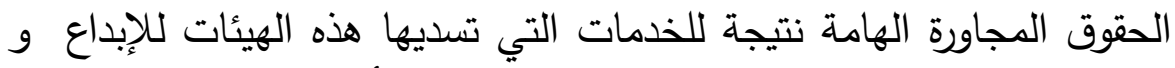

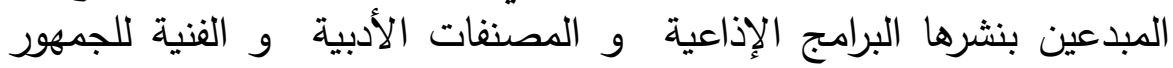

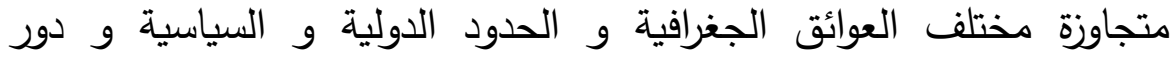

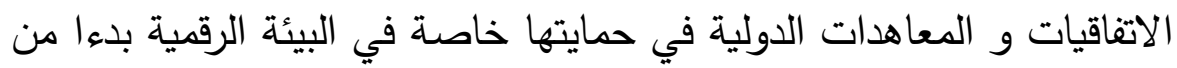

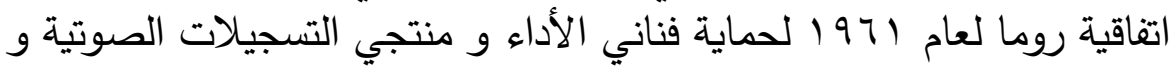

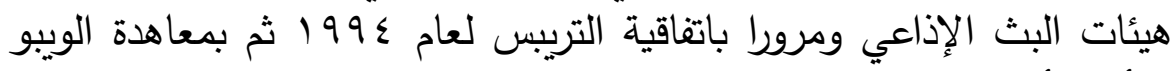

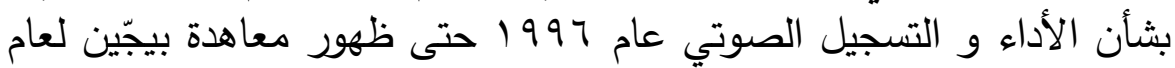

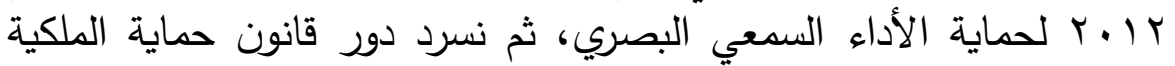

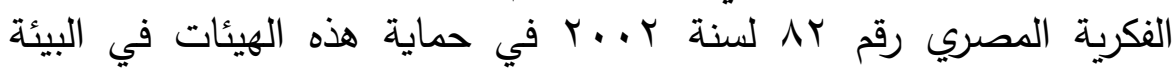

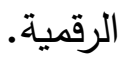

\section{الفصل التمهيدي: ماهية البيئة الرقمية:}

تواجه هيئات البث الإذاعي في البيئة الرقمية المتشابكة عددا كبيرا من البئه

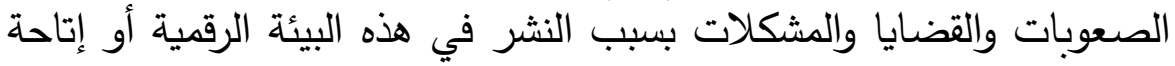

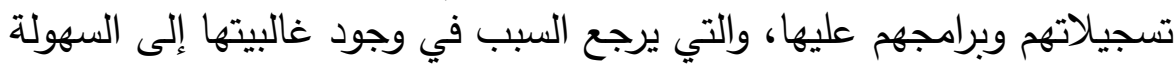


التي يمكن من خلالها استتساخ المواد المنشورة إلكترونيا على الإنترنت وقلة التكاليف المالية التي تستلزم ذلك.

\section{تعريف البيئة الرقمية:}

كما عرفها أحمد حسين بكر المصري: المئية (تلك التي يجري تناول

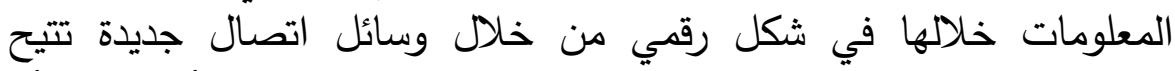

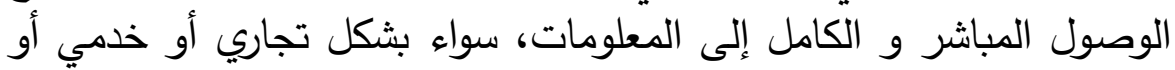

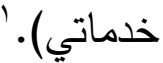

يرى تيلي أن المكونات الأساسية التي يجب توفرها في البيئة الرقمية

المعلومة على الثكل الرقمي

التكنولوجيات الحديثة لنقل المعلومات و الاتصال

الوسائل التقنية المستعملة من قبل المستعمل للوصول إلى

المعلومة. الوسئل

فالبيئة الرقمية هي ساحة العمل التي تقوم على الوسائل التكنولوجية

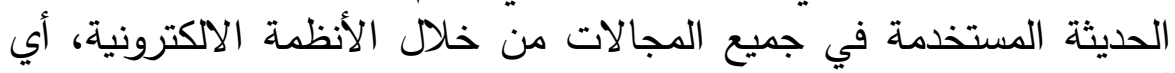
أنها تثمل كل الوسائل التقنية الحاملة للمصنف و و التي يتم نشرها بطريقة الكترونية. أنها تشيمل

\section{تقنية المعلومات: المحتوى والوسائل واتجاهات التطور:}

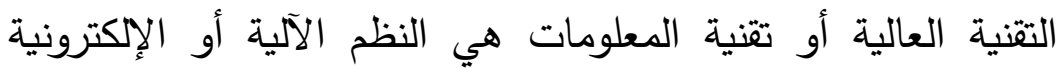

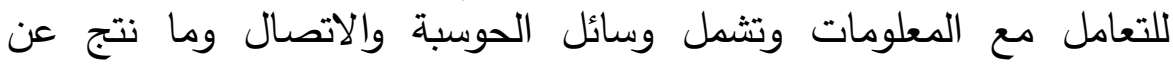
اندماجهما من وسائط تقنية عالية يعبر عنها بالعموم بنظام الكمبيوتر :

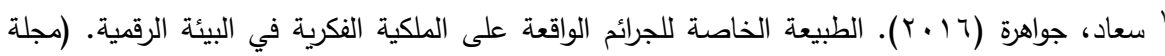

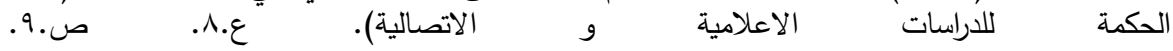
http://search.mandumah.com/Record/769999 r r المصدر السبق. ص. r. 


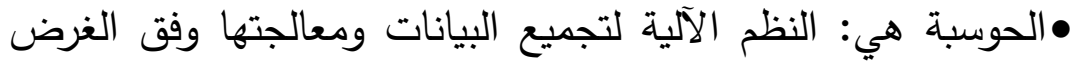

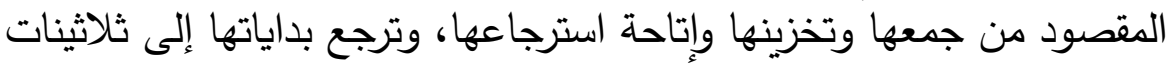

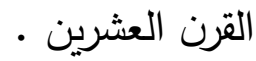

•والحاسوب أو الكمبيوتر، هو الأجهزة المادية والكيانات المنطقية

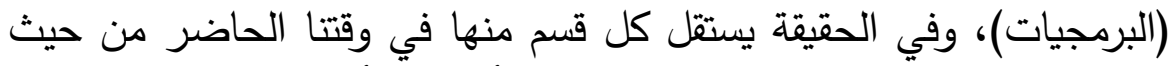

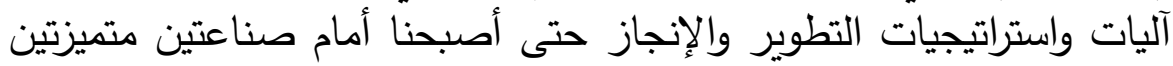
في حقل الكمبيوتر، صناعة الأجهزة (Hardware) وصناعة الأبرات البرمجيات

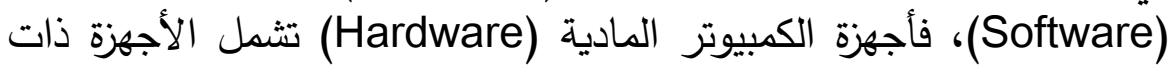

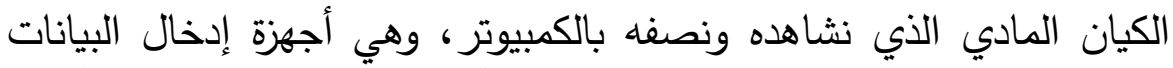

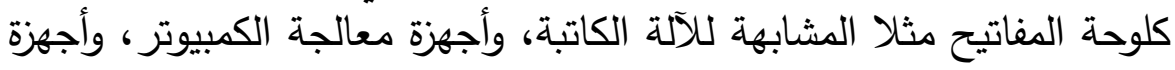

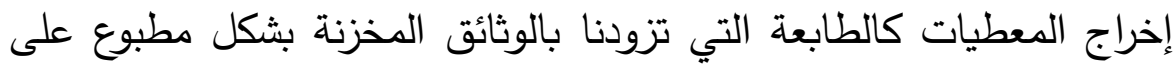

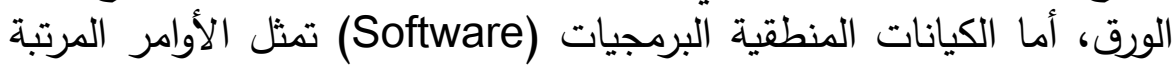

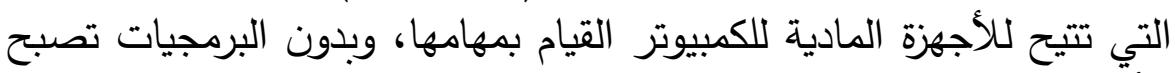
الأجهزة المادية مجرد كتل حديدية وبلاستيكية دون فائدة.'

المفهوم الثامل لنظام الكمبيوتز : إذن، تكنولوجيا المعلومات هي وسائل

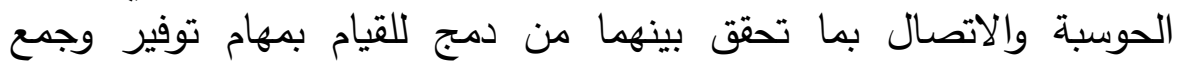
ومعالجة وتبادل المعلومات، وفي الحاضر من مراحل التطور التقني أصبح

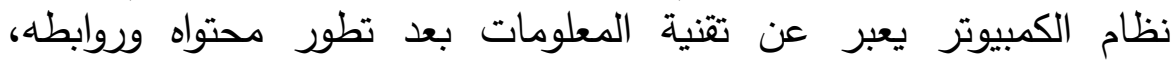

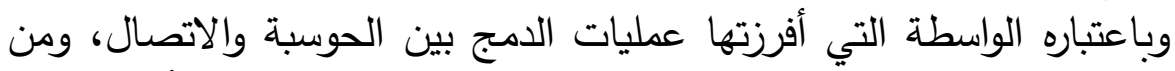

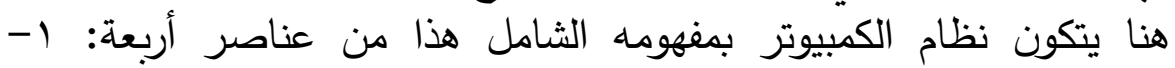

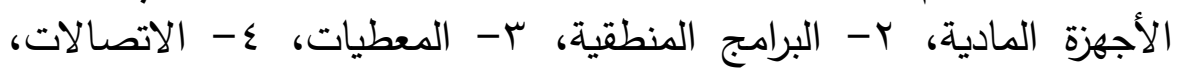

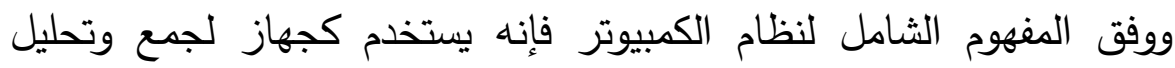

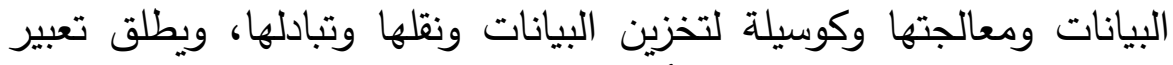

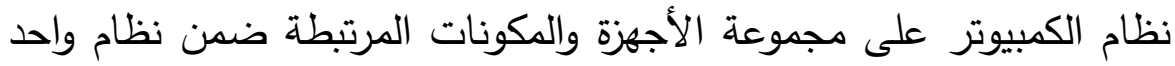

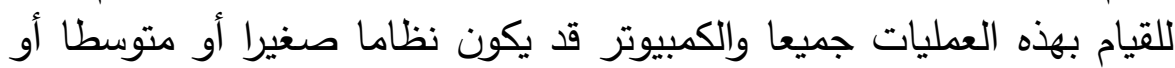
نظاما كبيرا، وأكثر أنظمة معالجة البيانات انتشارا الكمبيوترات الشخيرات ولكيات (PC)

بلهوشات، الزبير و رحايلي، محمد (10 • (1). حقوق المؤلف و الحقوق المجاورة في البيئة الرقمية : الحالة

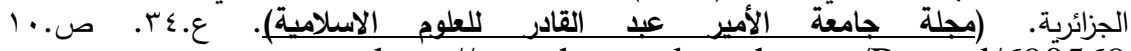
http://search.mandumah.com/Record/690569 
أصبح تعبير نظام الكمبيوتر يشمل ضمن مكوناته جميع الأجهزة اللازمة لإدخال البيانات ومعالجتها وحفظها واستخراجها (وهذه هي أجهزة الحوسبة) وتلك اللازمة لتبادل ونقل البيانات (أجهزة الاتصال المدمجة بالنظان والنام) وبمجوعها تسمى الأجهزة المادية Hardware إضافة إلى البـاتيات البرامج اللازمة للنظام وتسمى أيضا الكيانات المنطقية Software وتثمل نوعين رئيسين-

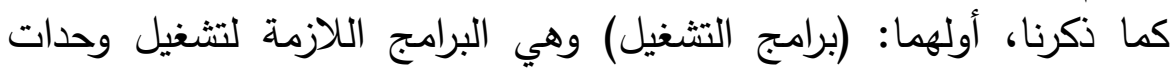

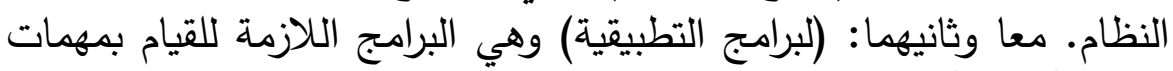

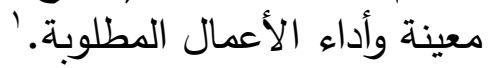

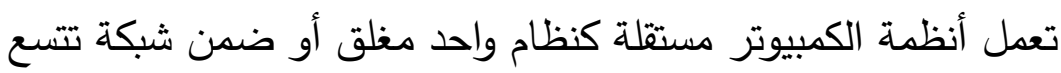
أو تضيق تربط أكثر من نظام العمل معا، وهو ما يعرف بشبكات آنطات المعلومات NETS

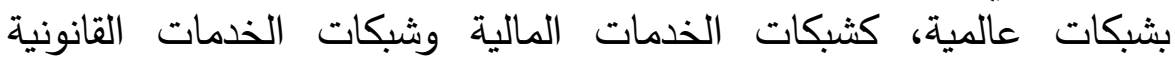
العالمية، وتعد الإنترنت INTERNET، شبكة الشبكات باعتبكات الثبارها الثبكة العالمية الأوسع مدى والأكثر من حيث المشتركين.

\section{تعريف الجريمة الالكترونية:}

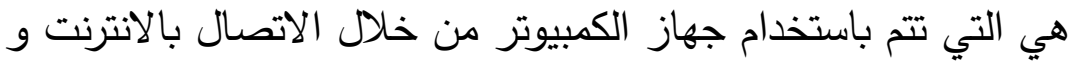

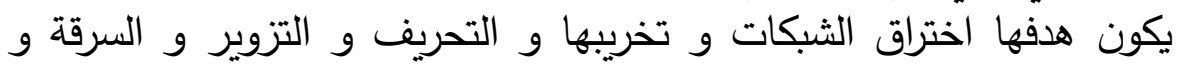
الاختلاس و القرصنة و سرقة حقوق الملكية.

هيئات البث:

عرف قانون حماية الملكية الفكرية المصري رقم هيئات البث بقوله أن هيئة الاذاعة : كل شخص أوفية أو جهة منوط بها أو الو مسئولة

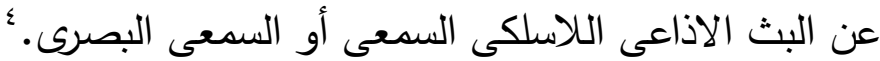

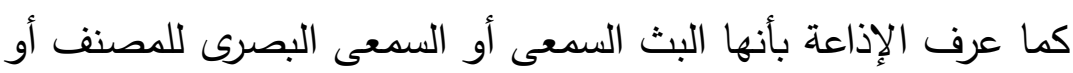

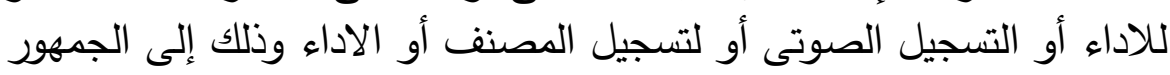

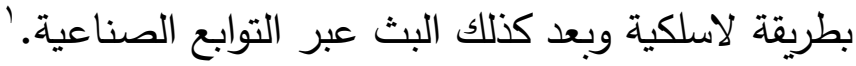

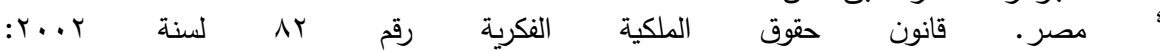

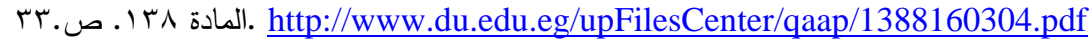


وهنا نلاحظ تجاهل المشرع المصري للبث عبر الانترنت.

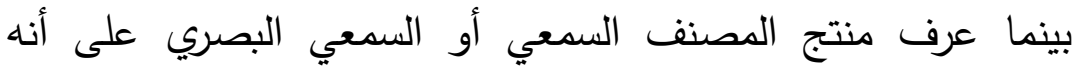

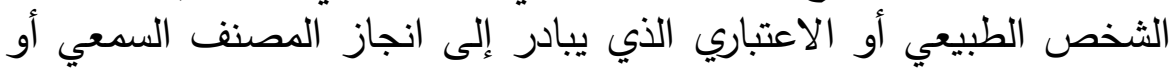

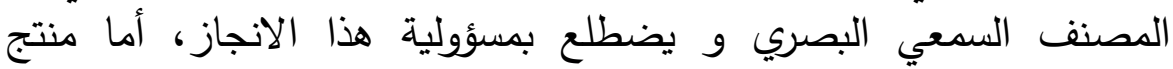

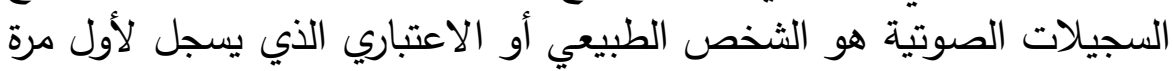

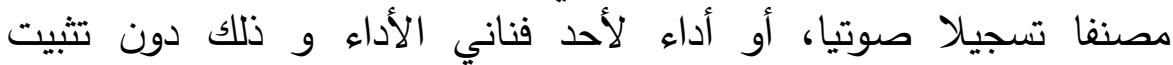

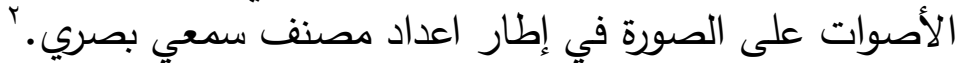

$$
\text { الحقوق المقررة للهيئات البث الأول }
$$

اتفاقية روما لحماية فناني الأدائ و منتجي التسجيلات الصوتية (الفونوغرام) و هيئات البث الإذاعي

نتيجة انتشار صناعة الفونوغرامات في مطلع الستينات و كثرة

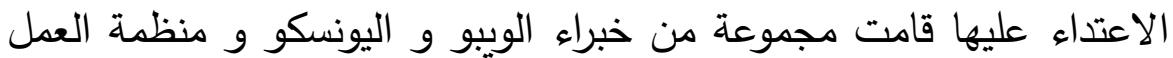

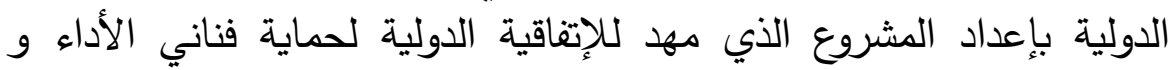

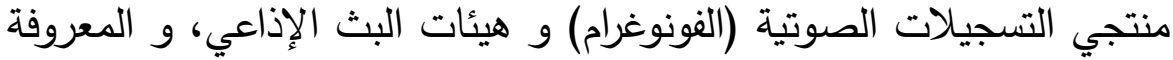

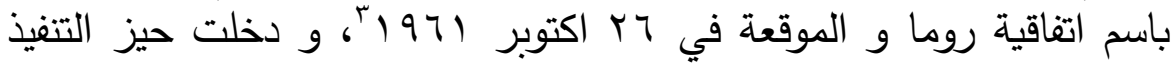

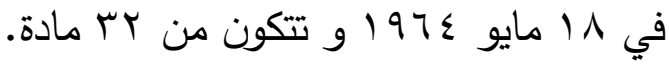

\section{الحقوق الشمولة بالحماية بالنسبة لهيئات الإذاعة كجهة إنتاج و كهيئة إذاعة}

في اتفاقية روما:ـ

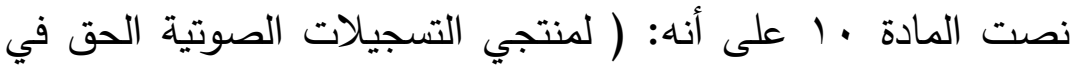
التصريح بالاستنساخ المباشر أو غير الهات المباشر لتسجيلاتهم الصوتية أو في حظره)؛

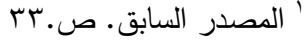

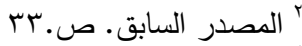

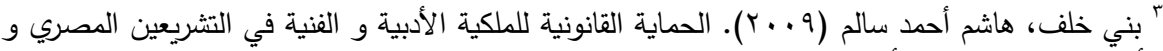

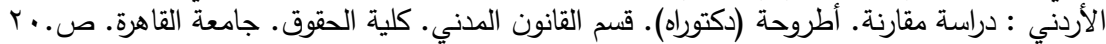

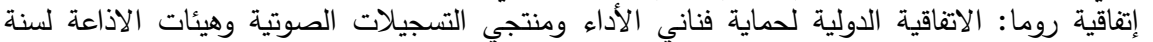
1971 
وقد تضمنت المادة r ا من الاتفاقية أنه يتم دفع مكافأة مالية عادلة

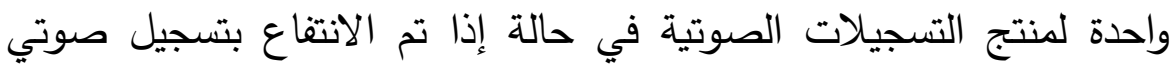
منشور لأغراض تجارية أو بنسخة عن ذلك التسجيل الصوتي لإذاعته أو لنقله

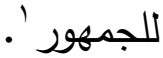

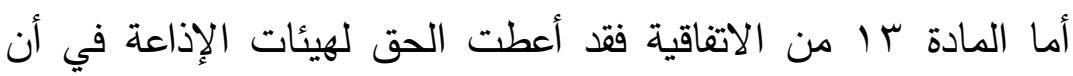

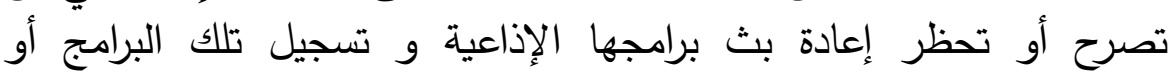

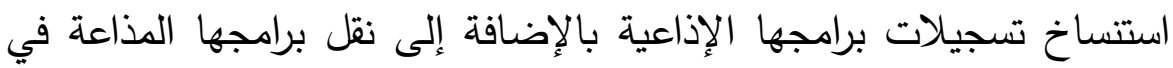

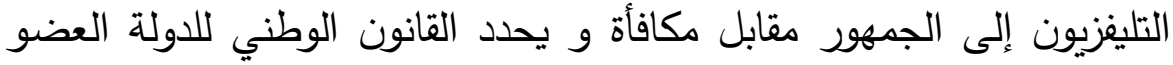

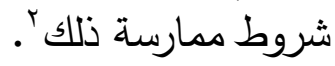

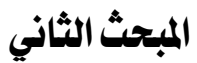 \\ اتفاقية الجوانب المتصلة بالتجارة من حقوق الملكية الفكرية و المعروفة} بالتزيبس

اتفاقية التريبس هي اتفاقية دولية تختص بحماية الكثير من أشكال

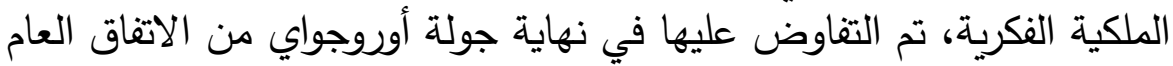

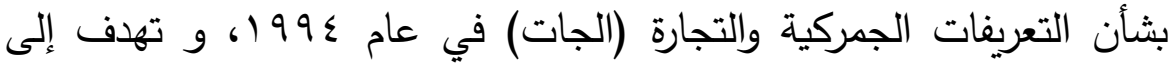

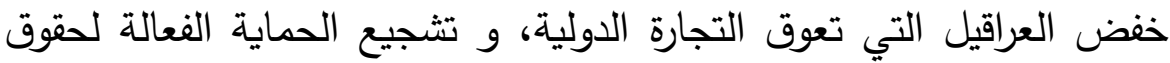

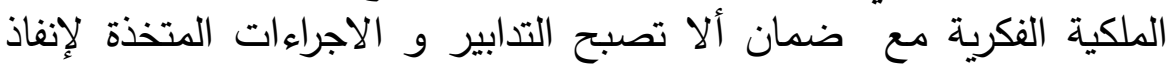

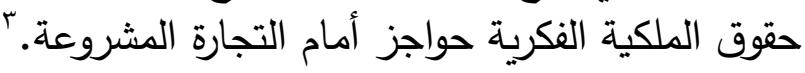

\section{الحقوق الشمولة بالحماية بالنسبة لهيئات الإذاعة كجهة إنتاج و كهيئة إذاعة} في اتفاقية التريبس:-

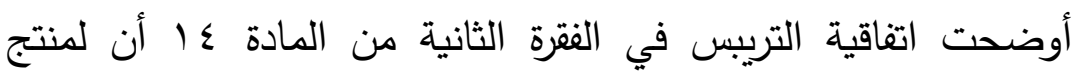

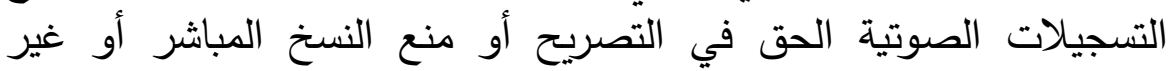

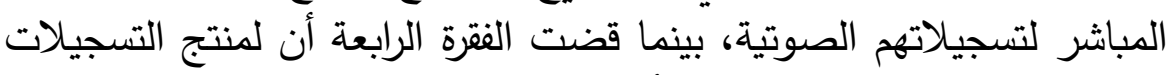

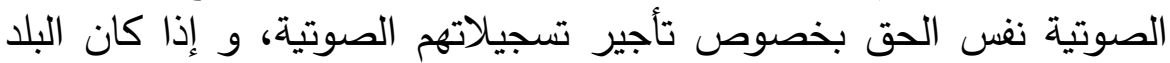

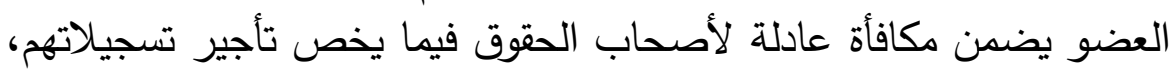


فيجوز مواصلة هذا النظام بشرط ألا يلحق ذلك ضرر مادي بحقوق النسخ

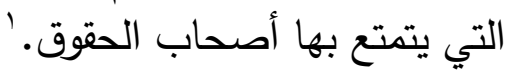

كما بينت الاتفاقية في الفقرة الثالثة للمادة ذاتها أن لهيئات الإذاعة الحق

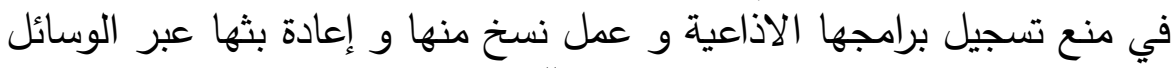
اللاسلكية و نقلها للجمهور دون موافقتها.' براعل

\section{المبحث الثالث}

\section{معاهدة الويبو لحماية الأدائ و التسجيل الصوات الصوتي}

اختمت المنظمة العالمية للملكية الفكرية (الويبو) في جنيف معاهدتين

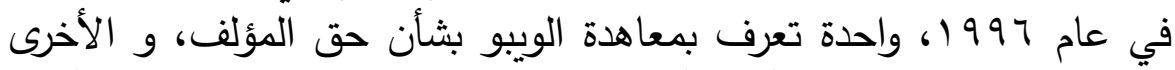

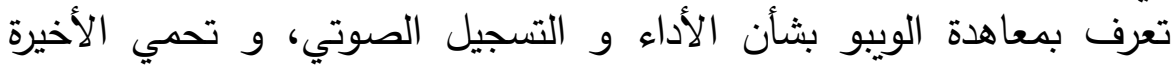

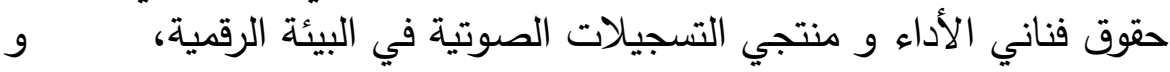

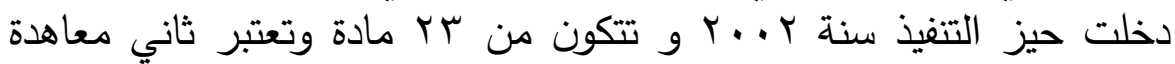
تختص بالانترنت.

و يشار إلى معاهدتي الويبو باسم (معاهدتي الانترنت) لأنهما يوفران

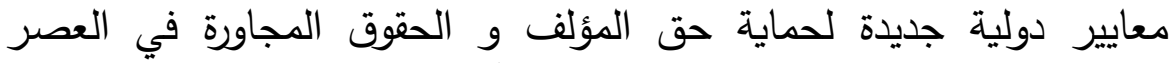

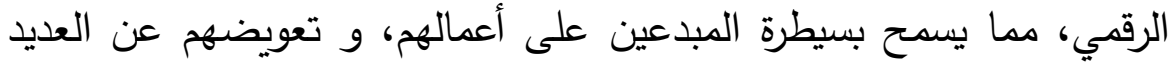

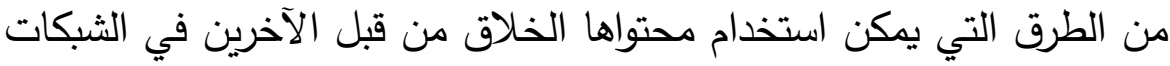

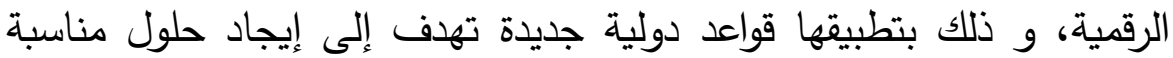

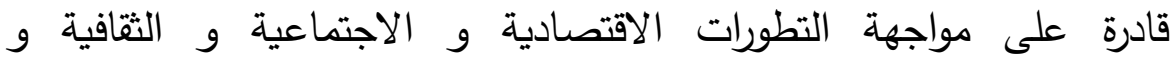

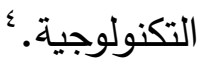




\section{الحقوق الشمولة بالحماية بالنسبة لهيئات الإذاعة كجهة إنتاج و كهيئة إذاعة

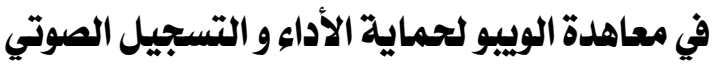

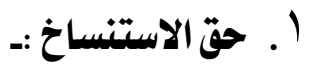

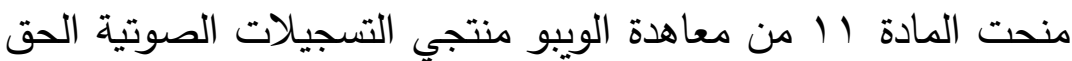

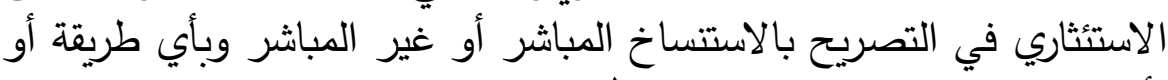

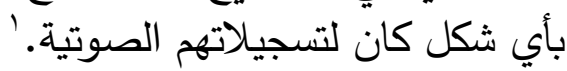

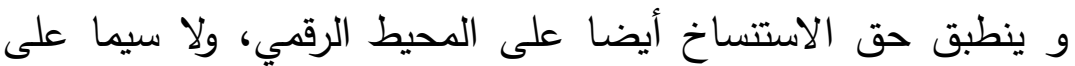
الانتفاع بأوجه التسجيلات الصوتية في شكل رقمي. الانيا

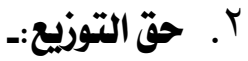

منحت أيضا المادة r ا من معاهدة الوبيو لمنتجي التسجيلات الصوتية

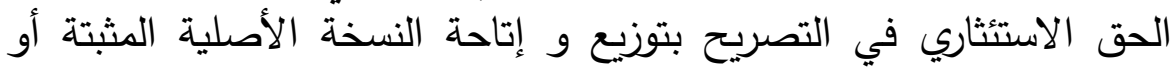

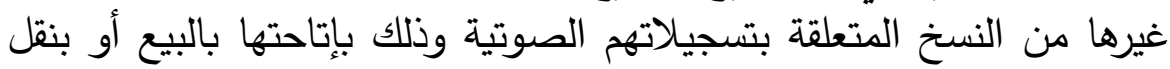

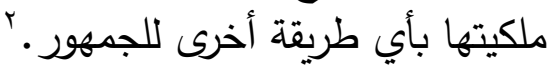

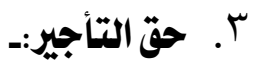

منحت معاهدة الويبو منتجي التسجيلات الصوتية الحق الاستئثاري في

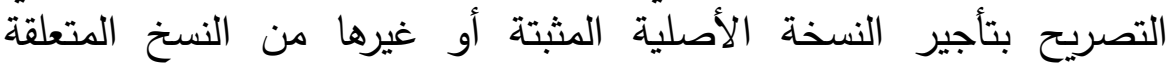

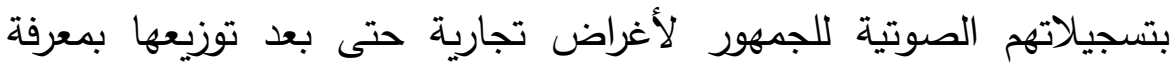

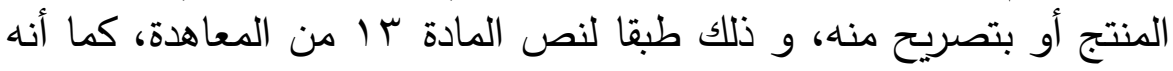

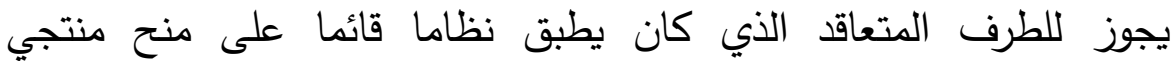
التسجيلات الصوتية مكافأة عادلة مقابل تأجير نسخ عن تسجيل نطيلاتهم الصوتية

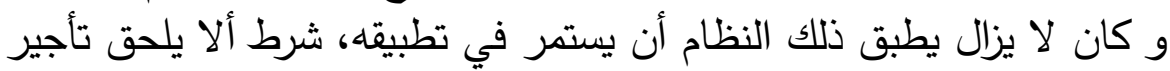

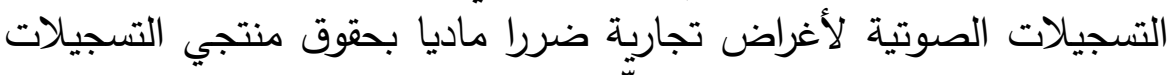
الصوتية الاستئارية في الاستنساخ. 


\section{؟. حق إتاحة التسجيلات الصوتية:.}

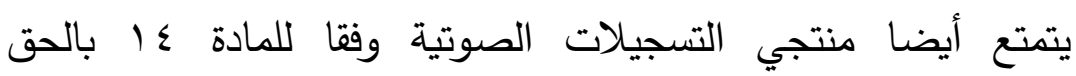

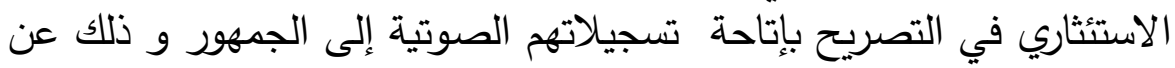

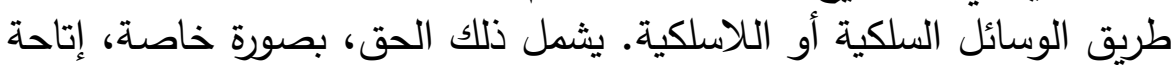
التسجيل الصوتي عبر الإنترنت بناء على الطلب وبشكل متفاعل.'

\section{○. الحق في مكافأة مقابل الإذاعة أو النقل إلى الجمهور:-}

تضمنت معاهدة الويبو في الفترة الأولى من المادة 10 نصوصا تتعلق

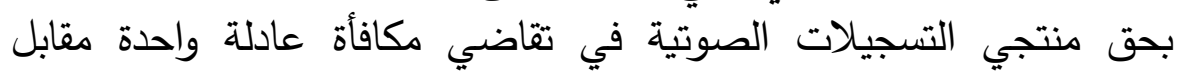
الانتفاع المباشر أو غير المباشر بالتسجيلات الصوتية التي لتئي تلشر لأغراض تجارية كإذاعتها أو نقلها أو نقلها إلى الجمهور بأبي طريقة كانت. كما نصت المادة ذاتها على حق الدول الأطراف بالمعاهدة في أن

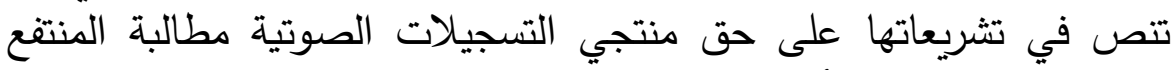

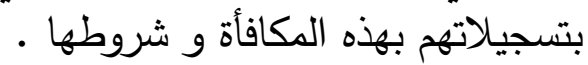

كما أجازت للأطراف المتعاقدة أن تعلن بموجب إخطار تودعه لاى النى النها

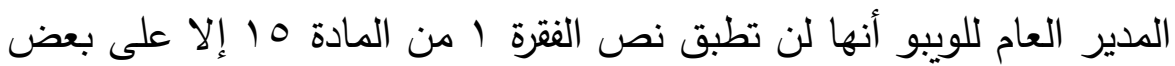

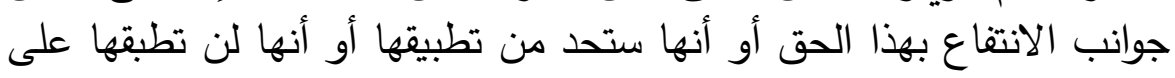
الاطللاق.

تعتبر منشورة لأغراض تجارية التسجيلات الصوتية التي أتيحت

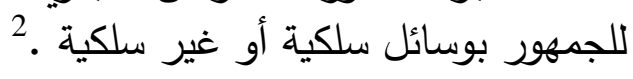

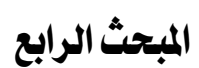 \\ معاهدة بيجيَّن بشأن الأدائ السمعي البصري}

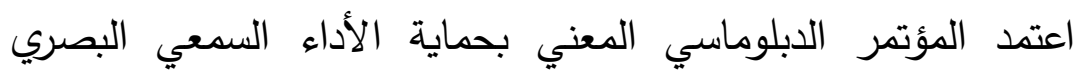

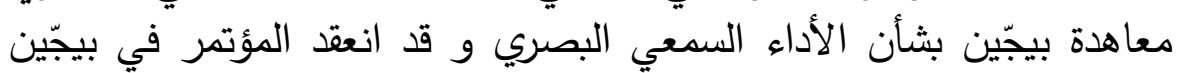

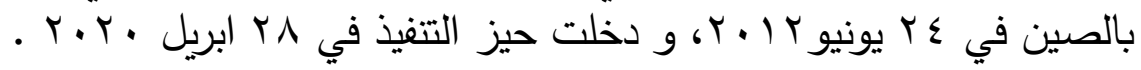


وتتناول المعاهدة حقوق الملكية الفكرية لفناني الأداء في أوجه أدائهم

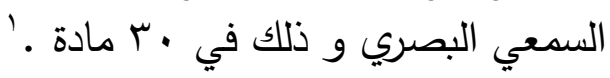

وتهدف المعاهدة إلى تطبيق قواعد دولية جديدة يكون من شأنها إيجاد

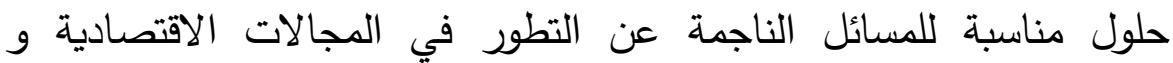

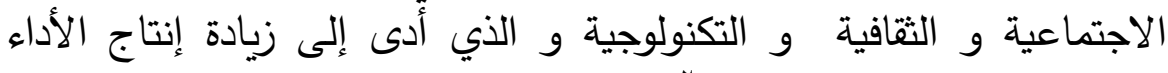
السمعي البصري و الانتفاع به.

\section{الحقوق الشمولة بالحماية بالنسبة لهيئات الإذاعة كجهة إنتاج و كهيئة إذاعة}

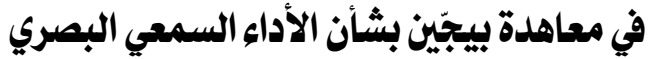

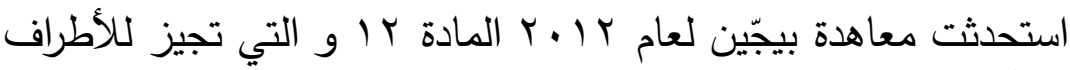

المتعاقدة أن تتص في قوانينها الوطنية بعد موافقة فنان الأداء على على تلى تثبيت أدائه السمعي البصري في تثبيت سمعي بصري فئي فإن جميع حقوقه التصريح

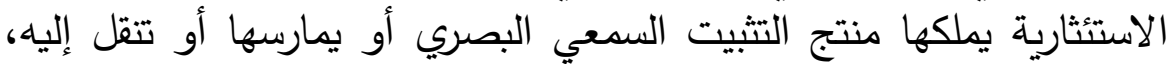

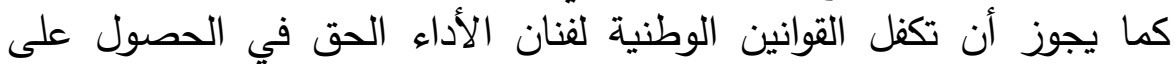

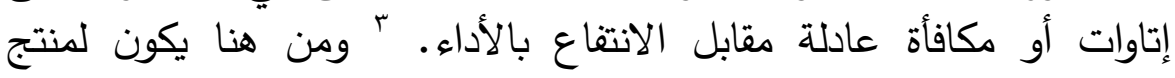
التسجيل السمعي البصري الحقوق التالية:

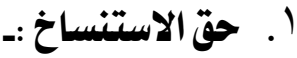

منحت معاهدة بيجّين لمنتج التسجيل السمعي البصري الذي الذي انتقلت إليه

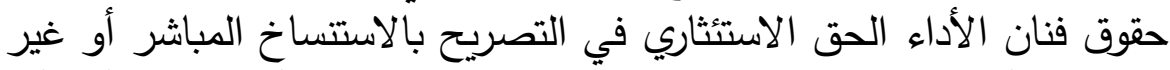

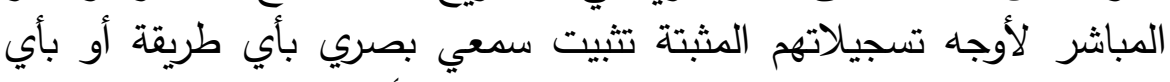

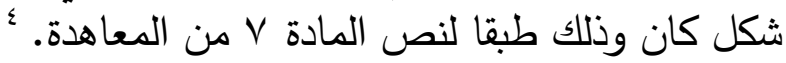

و ينطبق حق النسخ أيضا على المحيط الرقمي، ولا سيما على الانتفاع

$$
\text { بأوجه التسجيلات في شكل رقمي. }
$$

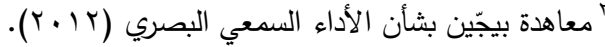

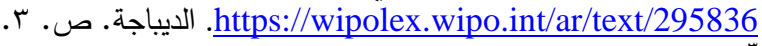




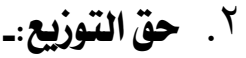

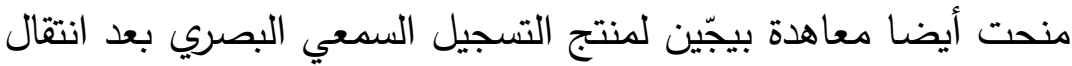

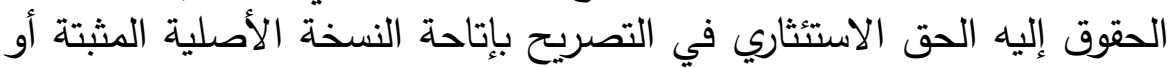

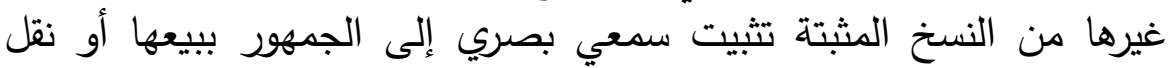

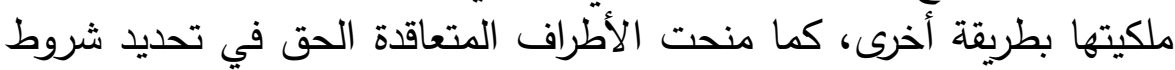

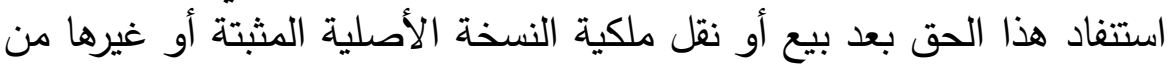

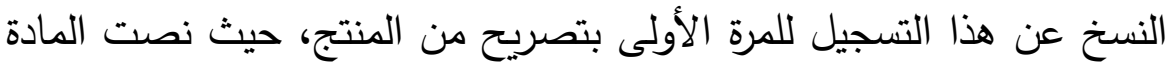
م على ذلك.

و ينطبق حق التوزيع أيضا على المحيط الرقمي، ولا سيما على إلى الانتقاع بأوجه التسجيلات في شكل رقمي.

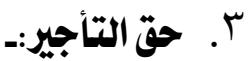

يتمتع منتج التسجيل السمعي البصري المنقول له حقوق فئان الهان الأداء

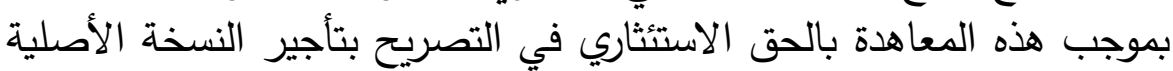

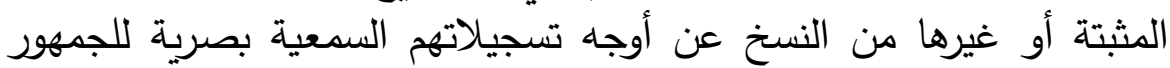

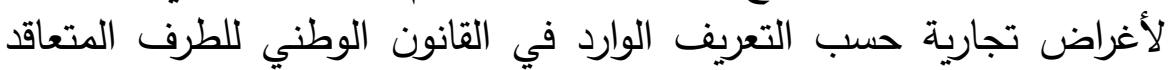

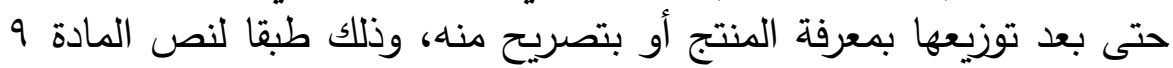

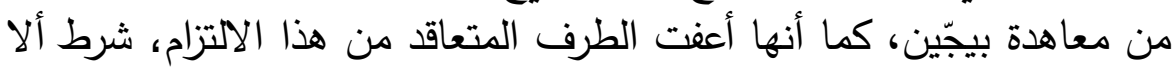

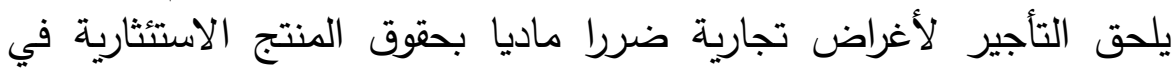
الاستنساخ. التانج

و ينطبق حق التأجير أيضا على المحيط الرقمي، ولا سيما على إلى الانتفاع بأوجه التسجيلات في شكل رقمي.

ع. حق إتاحة التسجيل:-

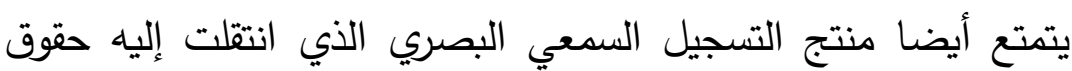

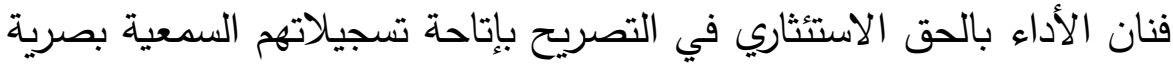


إلى الجمهور و ذلك عن طريق الوسائل السلكية أو اللاسلكية، حيث نصت

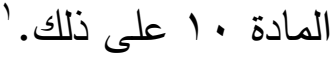

و ينطبق حق الاتاحة أيضا على المحيط الرقمي، ولا سيما على ألى الانتفاع بأوجه التسجيلات في شكل رقمي. الاناهة النيا

○. حق الإذاعة أو النقل للجمهور:-

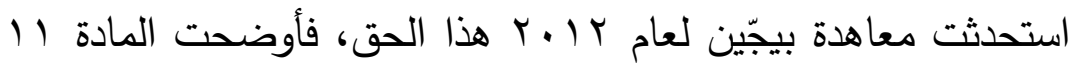

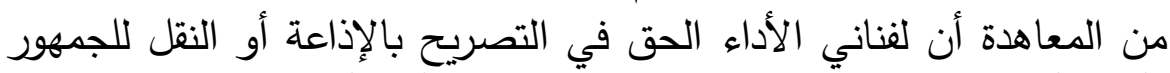

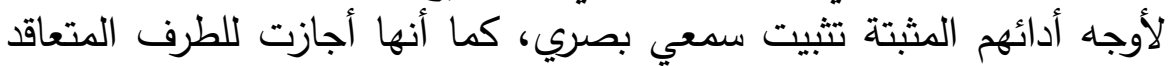

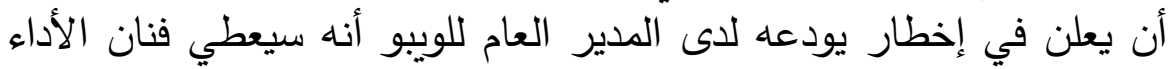

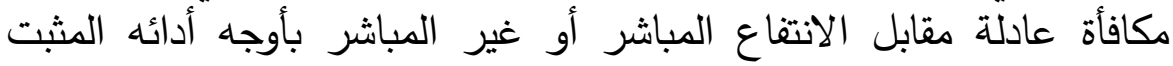

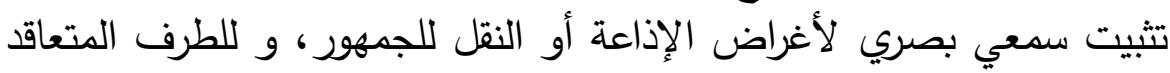

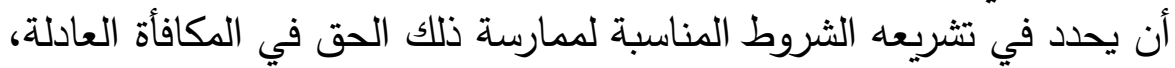

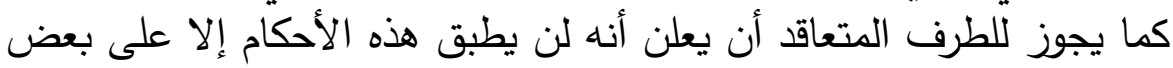

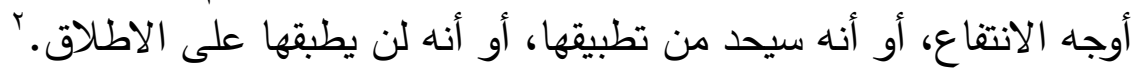

\section{المبحث الخامس \\ قانون حماية حقوق الملكية الفكرية المصري رقم rA لعام r..r:}

بعد انضمام مصر لمنظمة التجارة العالمية و الاتفاقيات الدولية التي حمئي

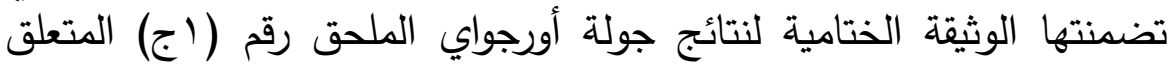

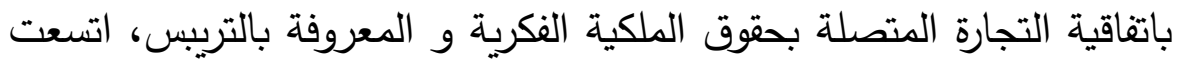

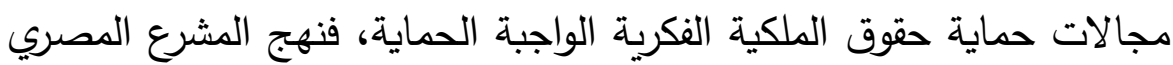

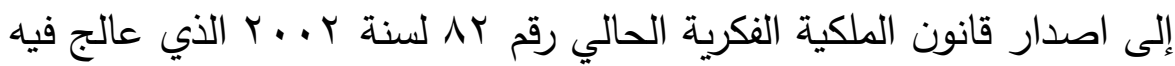

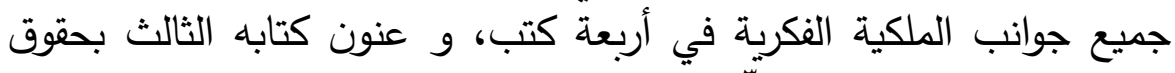
المؤلف و الحقوق المجاورة. 


\section{الحقوق الشمولة بالحماية بالنسبة لهيئات الإذاعة كجهة إنتاج و كهيئة إذاعة في قانوز حماية حقوق الملكية الفكرية المصري رقم rA لعام r..r..}

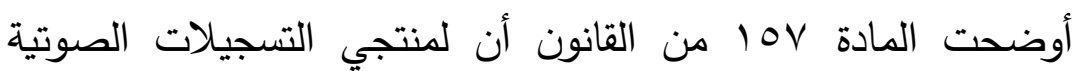

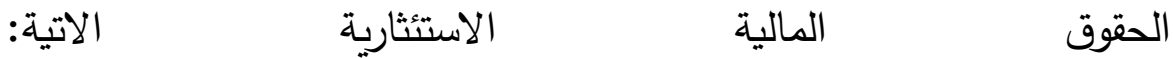

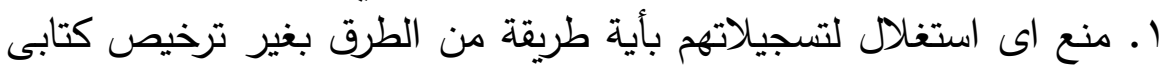

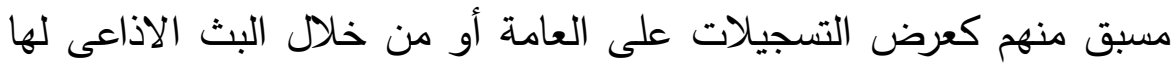
أو اتاحتها عبر الانترنت أو نسخها أو تأجيرها.

r. الاتاحة العلنية لتسجيل صوتى بوسائل سلكية أو لاسلكية أو عبر اجهزة

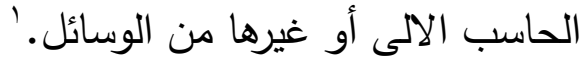

أما المادة 101 بينت أن لهيئات الاذاعة التمتع بالحقوق المالية

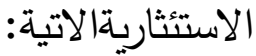

1. منح الترخيص باستغلال تسجيلاتهات r. منع أي توصيل لتسجيلاتها التليفزيونية لبرامجها إلى الجمهور بغاتهير

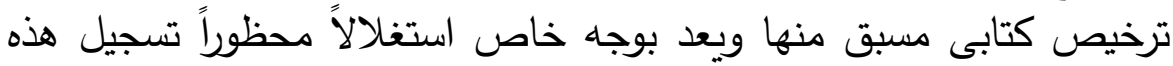

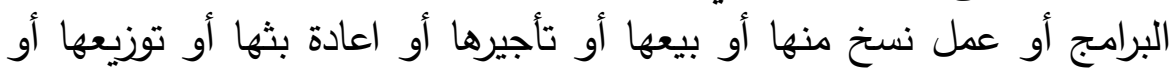

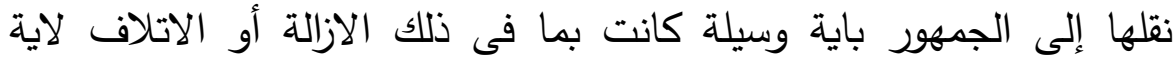
حماية تقنية لهذه البرامج كالتشفير أو غيره.

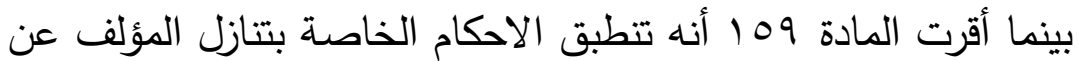

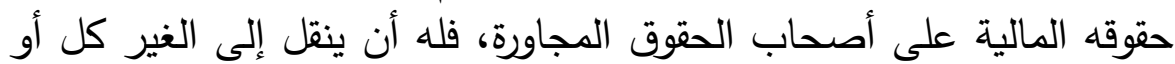

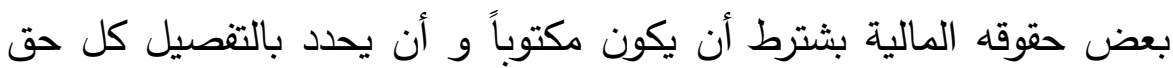

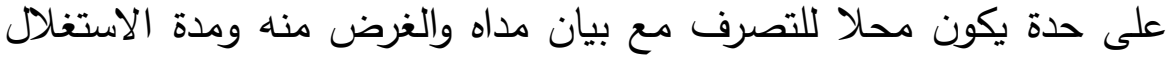

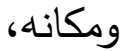

ومع عدم الاخلال بما نص عليه فى هذا القانون من حقوق استئثارية لفنانى الإنى

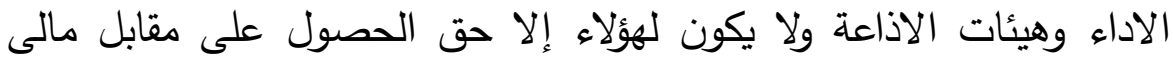

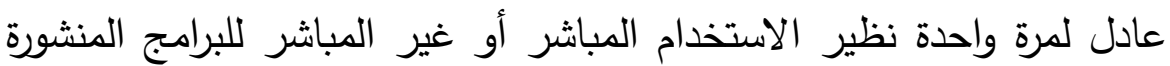

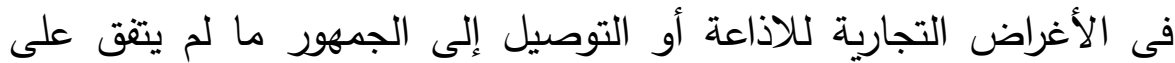
غير ذلك. 
كما يحق لهيئات الإذاعة أيضا بث المصنفات التي تؤدى في أي مكان

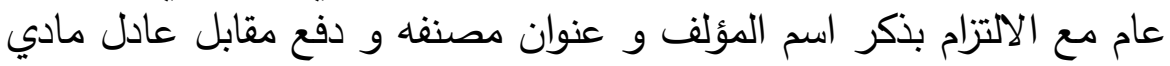

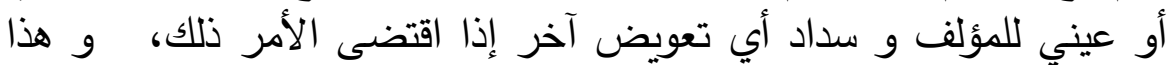

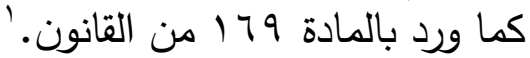

يكون المنتج طوال فترة استغلال المصنف سواء كان سمعي بصري

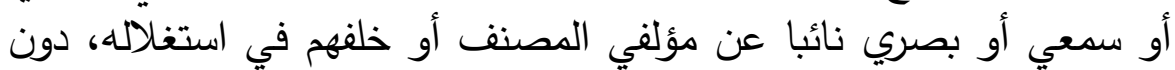

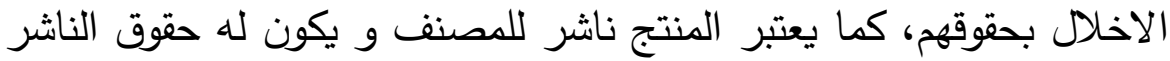

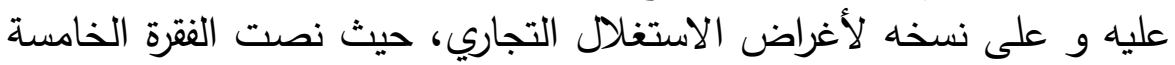

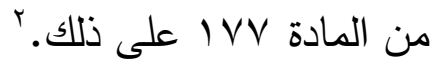

\section{الفصل الثاني الواني \\ الالتزامات الواردة في الاتفاقيات}

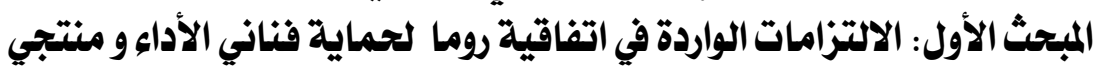
التسجيلات الصوتية (الفونوغرام) و هيئات البث الإذاعي الإني

نصت المادة rr من اتفاقية روما في فقراتها ا و و ب على أنه: (

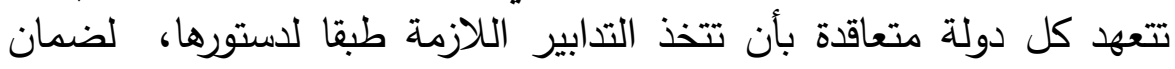

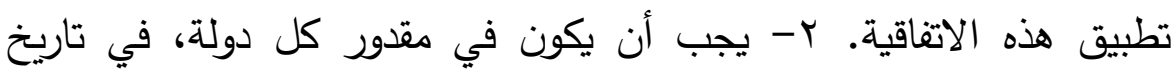
إيداعها لوثيقة التصديق أو القبول أو الانضمام، أن تطبق أنقات أحكام هذه الاتفاقية

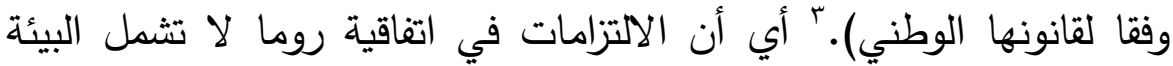

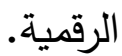

\section{المبحث الثاني \\ الالتزامات الواردة في اتفاقية الجوانب التصلية بالتجارة من حقوق الملكية}

\section{الفكرية و المعروفة بالتزيبس}

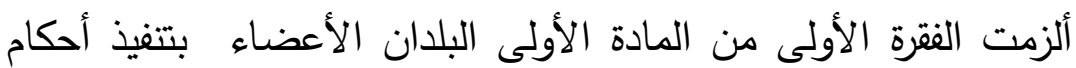

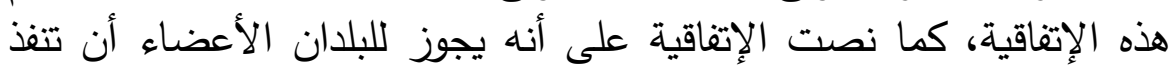


ضمن قوانينها حماية أوسع من الحماية التي يتطلبها هذا الاتفاق شرط ألا

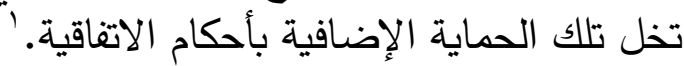

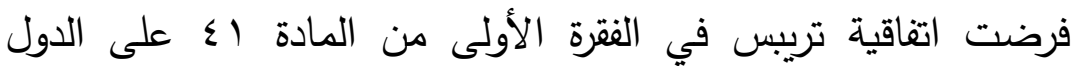
الأعضاء بضمان اشتمال قوانينها لإجراءات إنفاذ حقوق الملكية التئ الفكرية

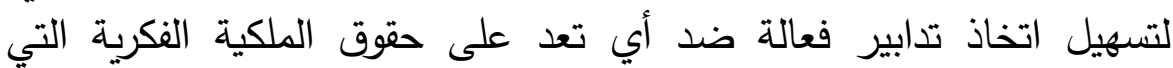

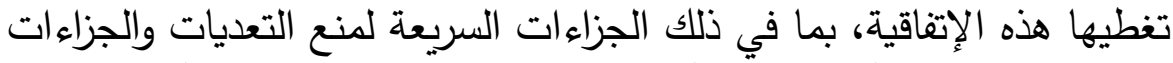

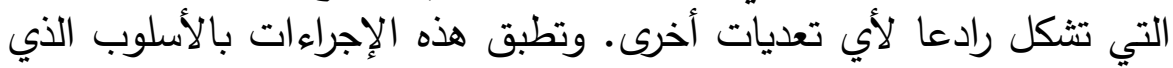
يضمن تجنب إقامة حواجز التجارة المشروعة ويوفر ضمات ضمانات ضدات ضد إساءة

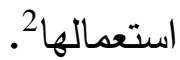

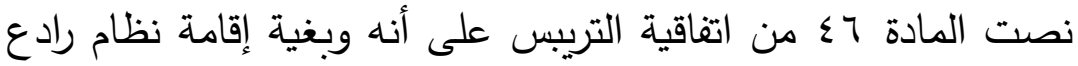

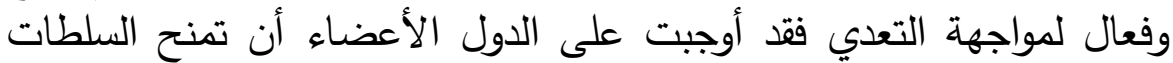
القضائية إمكانية إصدار الأوامر التالية: التصرف فوفي في السلع التي تشكل تعلي التعديا

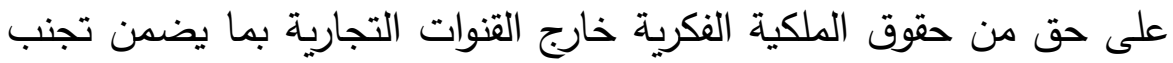

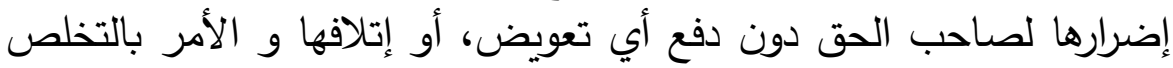

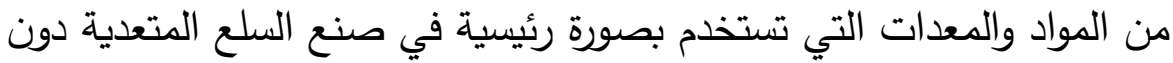

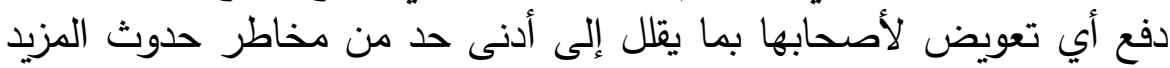

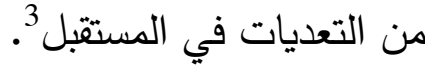

أجازت المادة V乏 من الاتفاقية للدول الأعضاء منح السلطات القضائية

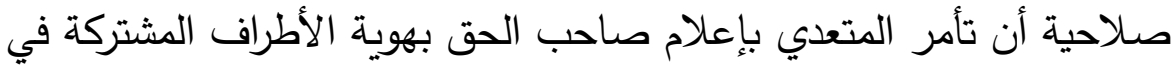
إنتاج أو توزيع السلع أو الخدمات المتعدية وقنوات التوزيع التي تستخدمهاب.

تلزم المادة اه من اتفاقية تريبس الدول الأعضاء بأن توفر في

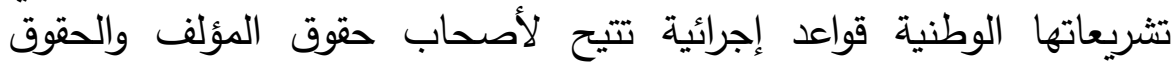

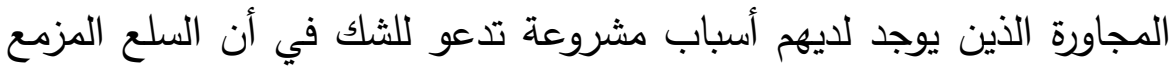

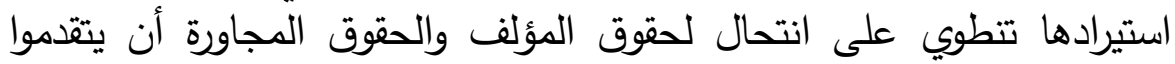

' اتفاقية التربس : اتفاقية الجوانب المتصلة بالتجارة من حقوق الملكية الفكرية. المصدر السابق. المادة // . 
بطلب كتابي إلى السلطات المختصة لكي توقف السلطات الجمركية إجراءات الافراج عن تلك السلع وتداولها بحرية.

حسب نص المادة ال7 من اتفاقية التريبس تلتزم الدول الأعضاء

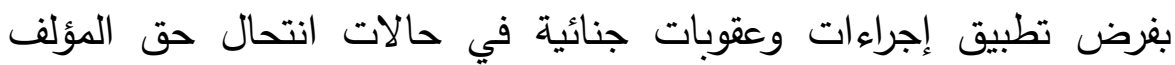
والحقوق المجاورة بشكل متعدد وعلى نطاق تجاري وتشمل تلك الجزاء الجزاء

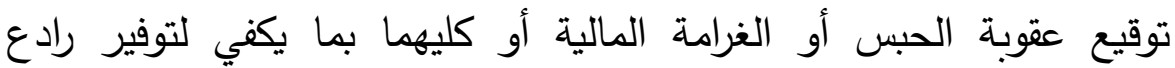
للتعدي، وتشمل أيضا في بعض الحالات المناسبة حجز السلع المخالفة أو أية مواد ومعدات تستخدم بصورة رئيسية في ارتكاب الجرم ومصادرتها والتهات واتلافها.

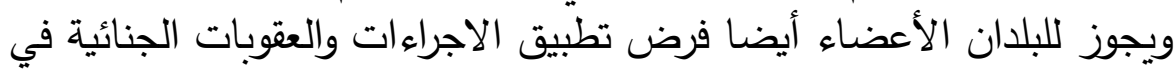

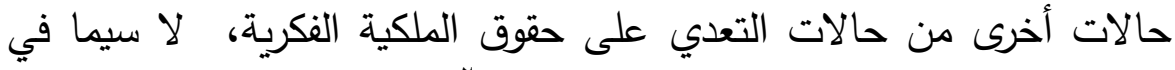

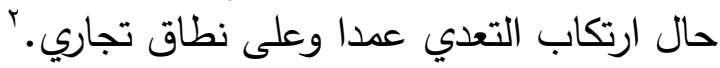

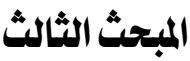

\section{الالتزامات الواردة في معاهدة الويبو لحماية الأدائ و التسجيل الصوتي}

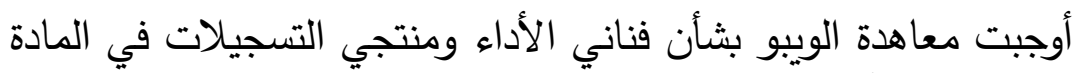

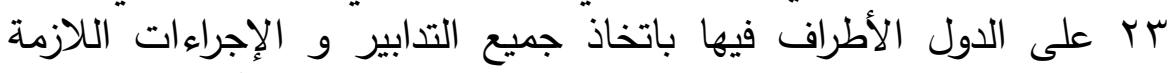

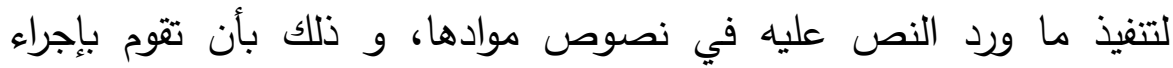
التعديلات و التغييرات اللازمة في تشريعاتها الوطنية بما يتوافق مع فئ الأهداف

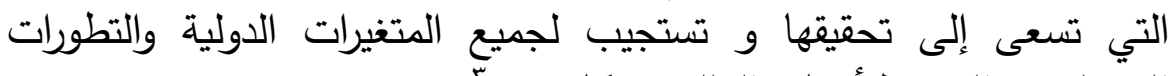
التكنولوجية التي تطرأ على العالم في كل يوم. تُعن

كما نصت معاهدة الويبو في المادة 11 على أن تلتزم الدول الأطراف

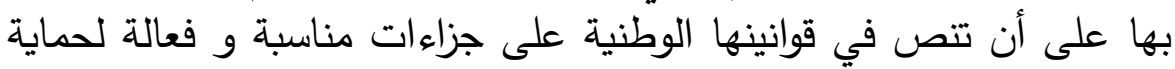

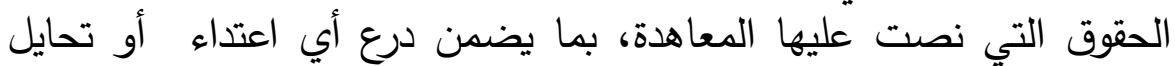

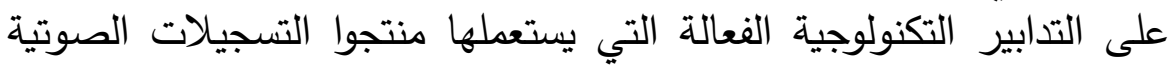
نتيجة ممارستهم لحقوقهم المشمولة بحماية هذه المعاهدة و الذي يكون من الذئي شأنه منع مباشرة أو ممارسة أي من الأعمال التي تتعلق بحقوق التها منتجي 
التسجيلات الصوتية دون تصريح منهم بممارستها أو إذا كان القانون لا يسمح بها، فيما يتعلق بتسجيلاتهم الصوتية.

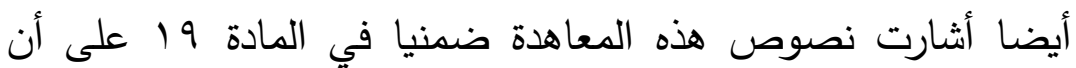

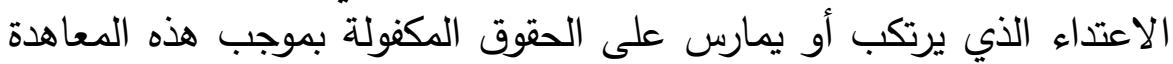

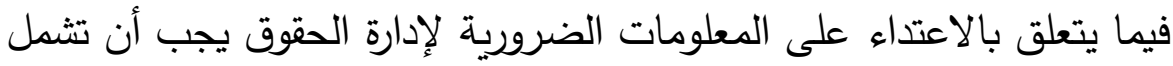

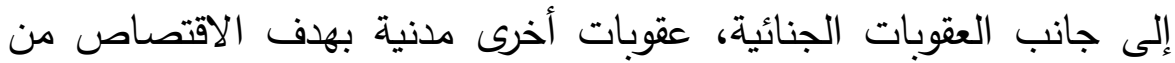

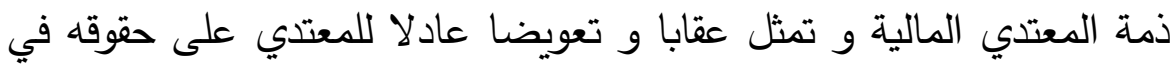

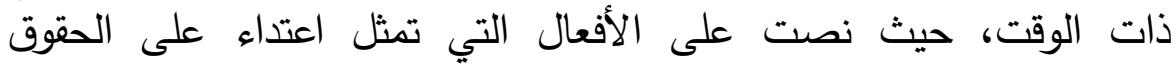

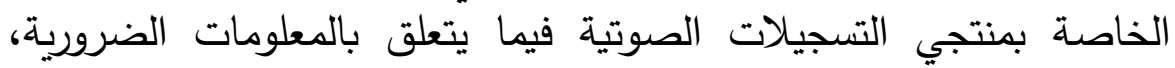

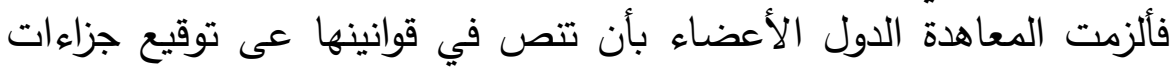

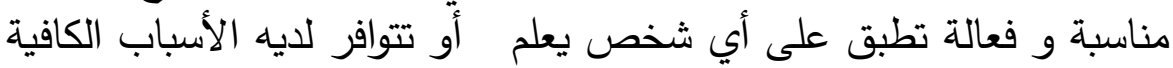

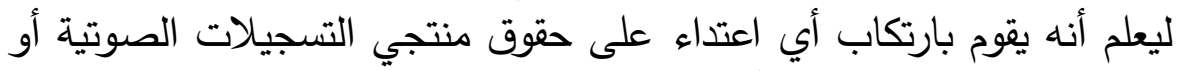

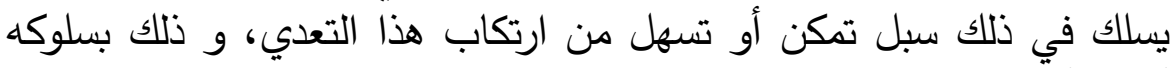

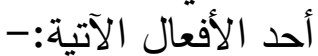

أن يقوم بدون إذن أو تصريح من صاحب الحق بحذف أو أو أون

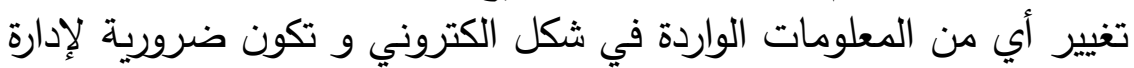
الحقوق.

أن يقوم بدون إذن أو تصريح من منتجي التسجيلات الصوتية

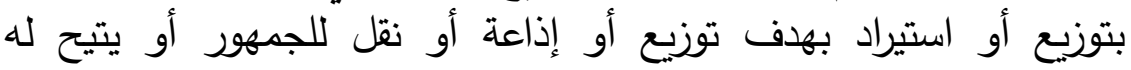

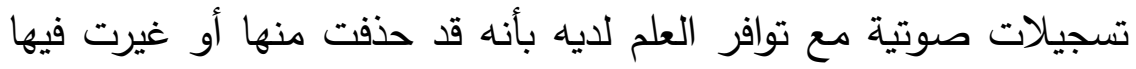

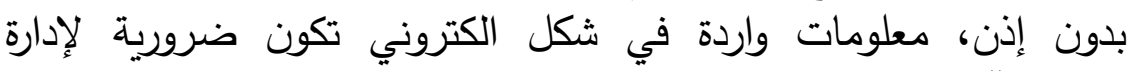
الحقوق.

وقد عرفت المعاهدة عبارة (المعلومات الضرورية لإدارة الحقوق)، بأنها

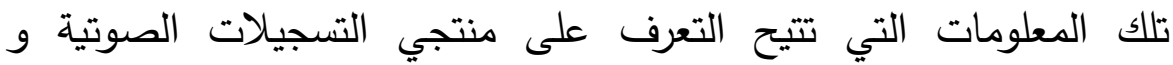

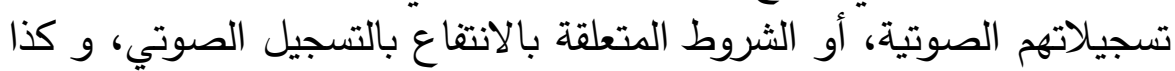

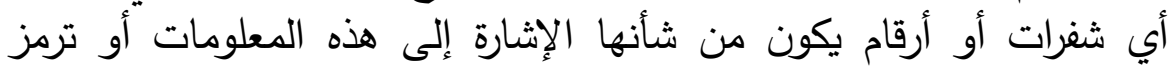


إليها، إذا كان أي من هذه العناصر المشار إليها مرتبطا أو مقترنا بنسخة عن إن إنها

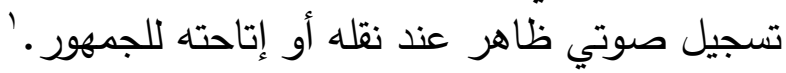

أي تتطلب معاهدة الويبو بشأن الأداء والتسجيل الصوتي من البلدان

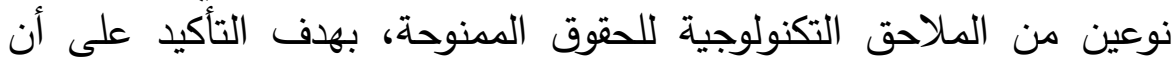

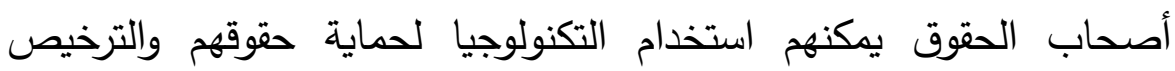

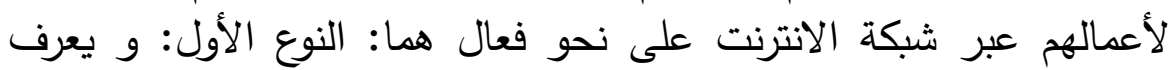

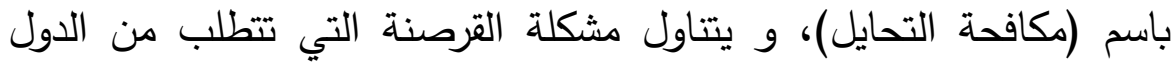

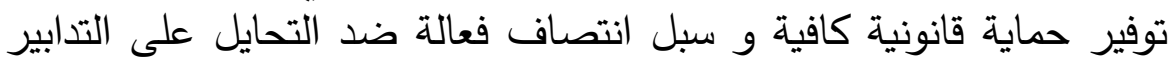

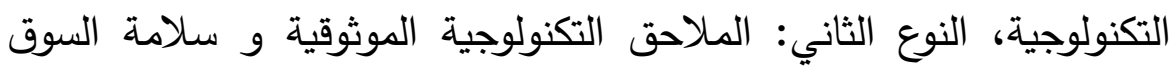

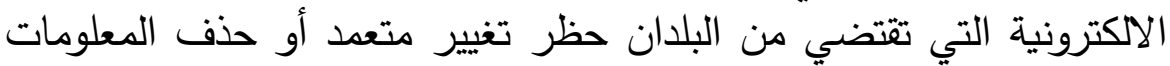

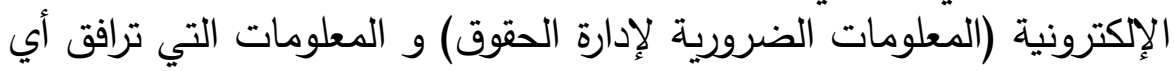

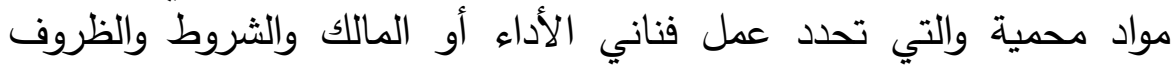

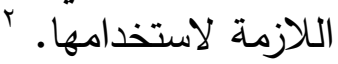

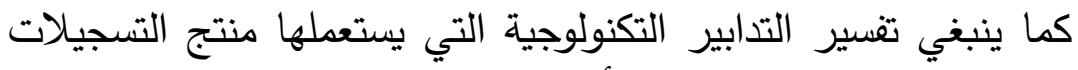

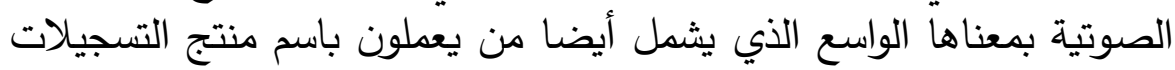

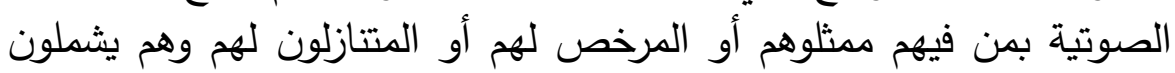

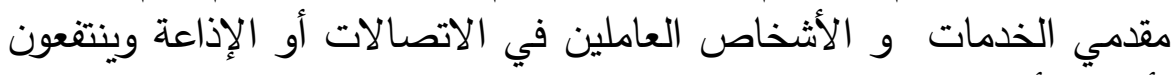

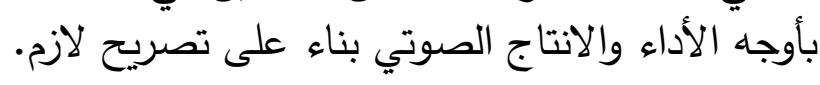

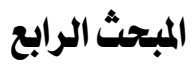 \\ في معاهدة بيجِيَن بشأن الأدائ السمعي البصري}

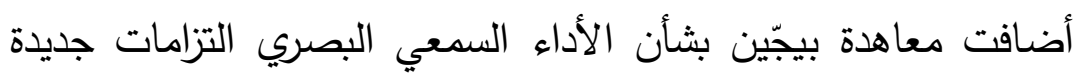

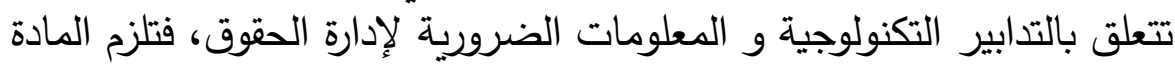

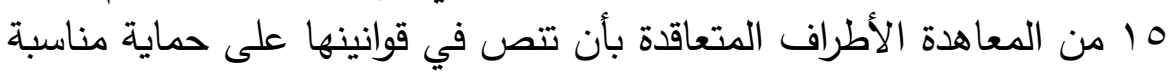

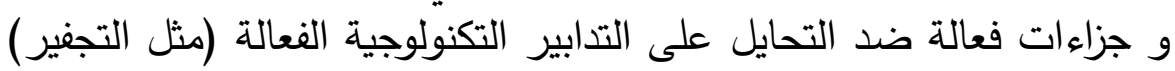
التي يستعملها فنانو الأداء بالارتباط بمارسة حقوقهم التي تمنع من مباشرة التيرة 
أعمال لم يصرح بها فنانو الأداء أو لم يسمح بها القانون فيما يتعلق بأوجه 'أدائهم.'

كما ينبغي تفسير التدابير التكنولوجية التي يستعملها فنان الأداء

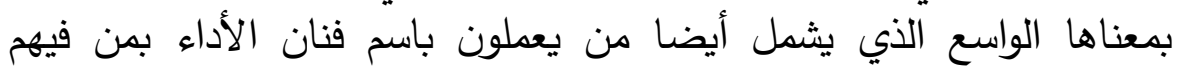

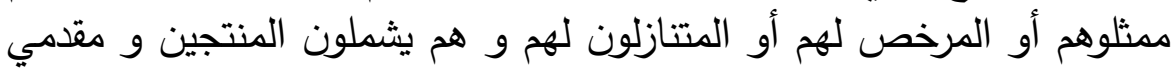
الخدمات و الأشخاص العاملين في الاتصالات أو الإذاعة و لون ينتفعون بأوجه

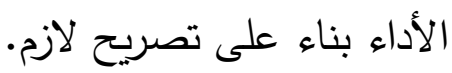

و كذلك ألزمت المادة 17 الأطراف المتعاقدة أن تتص في تشريعاتها

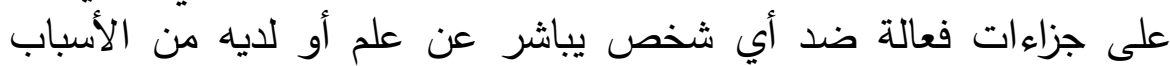

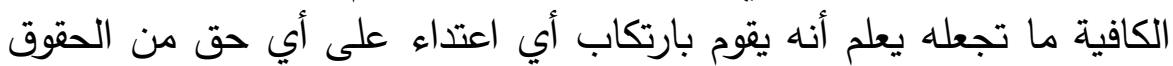

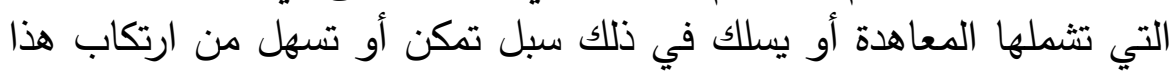
التعدي، و ذلك بسلوكه أحد الأفعال الآتية:-

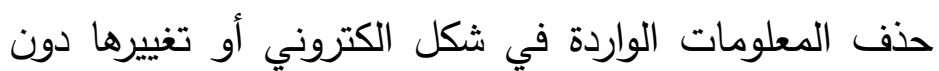

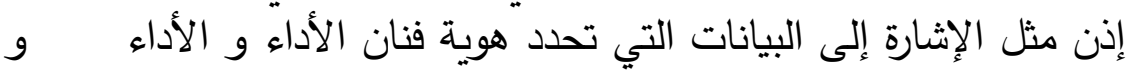

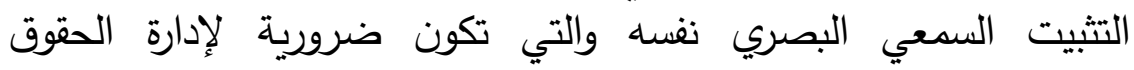
كالترخيص و جمع الإتاوات و توزيعها.

توزيع أو استيراد بهدف توزيع أو إذاعة أو نقل للجمهور أو أو دواء

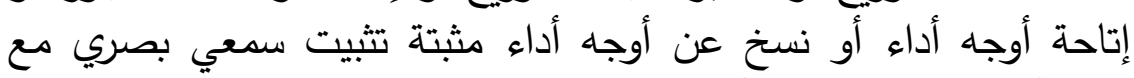

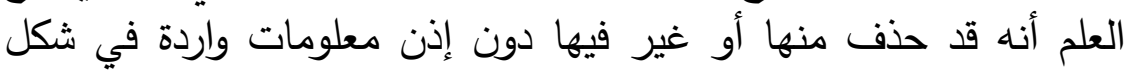
الكتروني و تكون لازمة لإدارة الحقوق.

وقد عرفت معاهدة بيجّين بشأن الأداء السمعي البصري عبارة

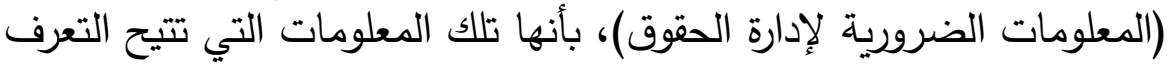

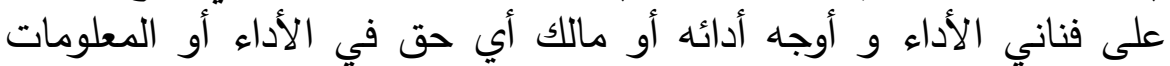

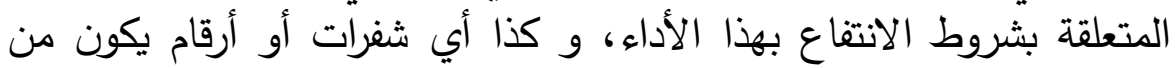

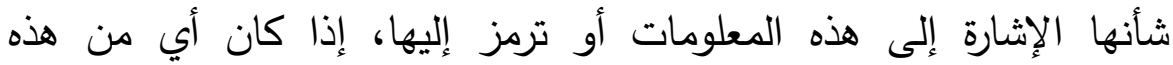


العناصر المشار إليها مرتبطا أو مقترنا بأداء مثبت في تثبيت سمعي

أوجبت معاهدة بيجّين في المادة • r على الدول الأطراف فيها باتخاذ

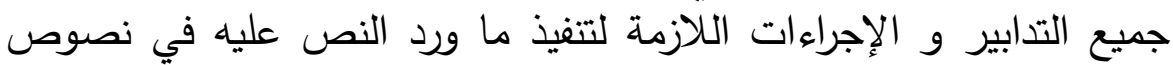

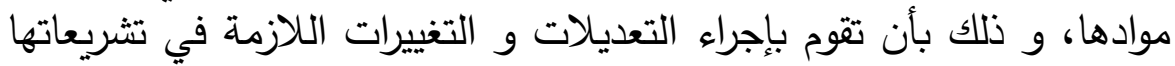

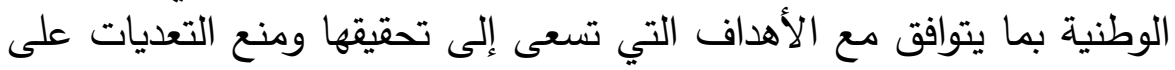

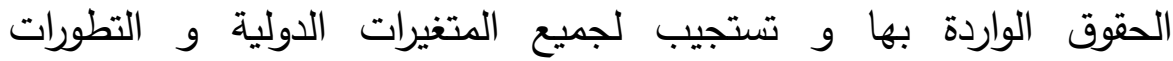

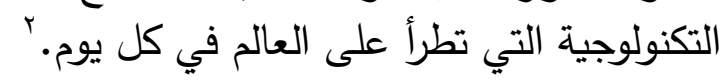

$\square$

\section{المبحث الخامس}

\section{الالتزامات الواردة في قانون حماية حقوق الملكية الفكرية المصري رقم به لعام}

$$
\text { r..r }
$$

أوضحت المادة V9 V9 من قانون حماية حقوق الملكية الفكرية المصري

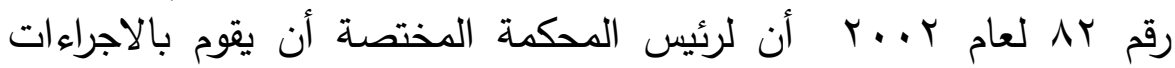

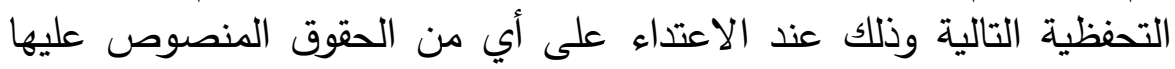
فى القانون و هي: التطان

•وقف نشر المصنف أو الاداء أو التسجيل الصوتى أو البرنامج الاذاعى أو عرضسه أو نسخة أو صناعته.

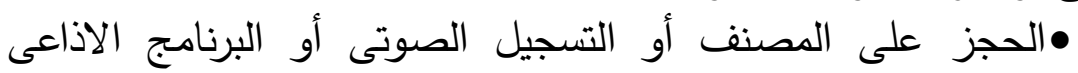

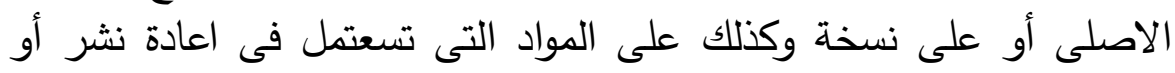

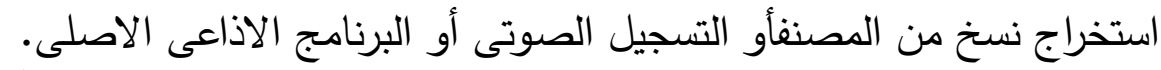

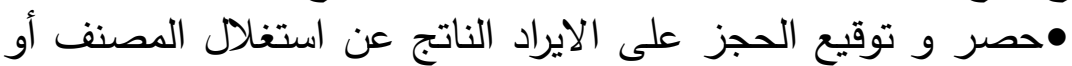
الاداء أو التسجيل الصوتى أو البرنامج الاذاعى. الايرات الت

كما أوجبت المادة 1/1 من القانون معاقبة المتعدي على الحقوق

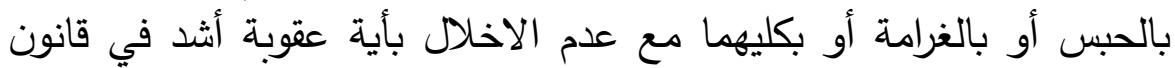
آخر إذا ارتكب أحد الأفعال التي تحمل تعدي على الحقوق و منها: 


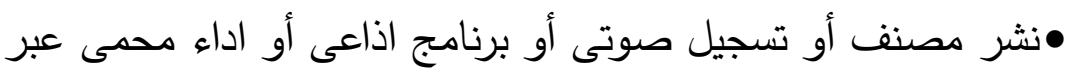

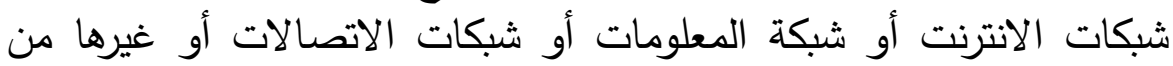

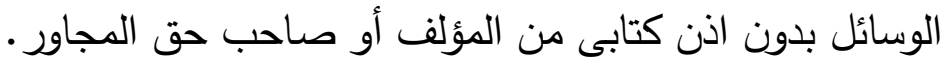

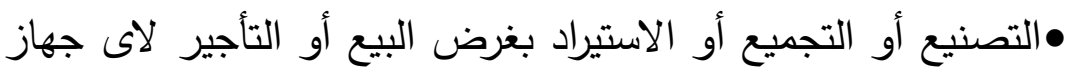

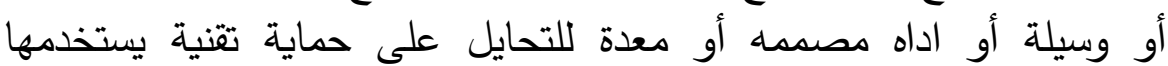
المؤلف أو صاجب الحق أو المجاه كاور كالتشفير أو غيره.

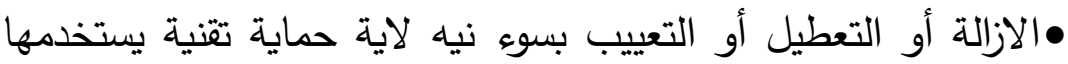
المؤلف أو صاحب الحق المجاور كالتشفير أو غيره.

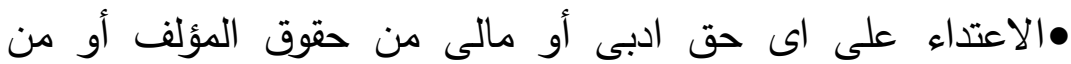

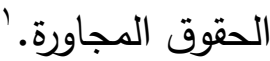

\section{الخاتمة:-}

تتاولنا في هذا البحث دراسة للاتفاقيات الدولية الخاصة بحماية هيئات البث الإذاعي في البيئة الرقمية، و هم التفاقية التريبس عام ع9 99 19، ومعاهدة

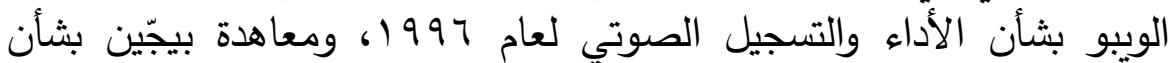

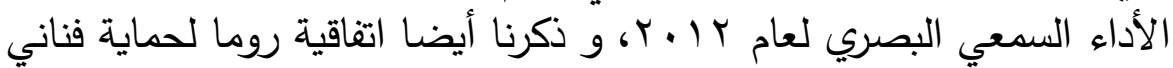

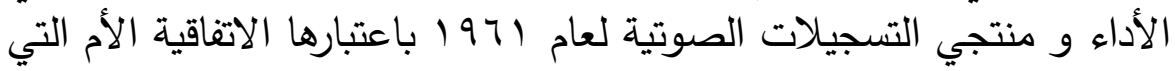

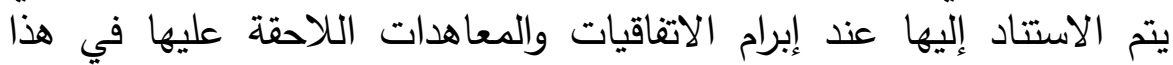

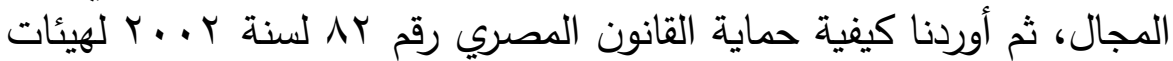

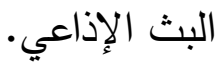

يتضح بالدراسة أن اتفاقية روما لا تواكب التطورات التكنولوجية الراهنة

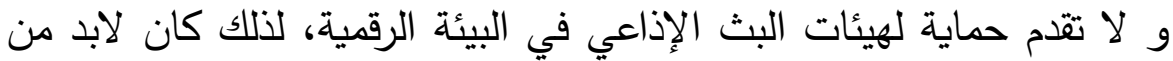

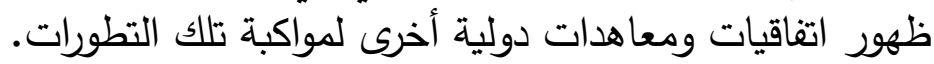

فجاءت اتفاقية الترببس و هي اتفاقية واسعة النطاق إذ تثمل العديد من

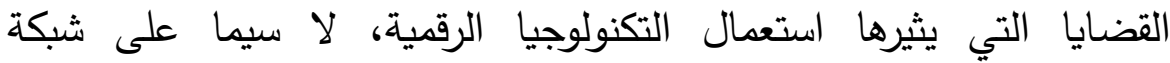

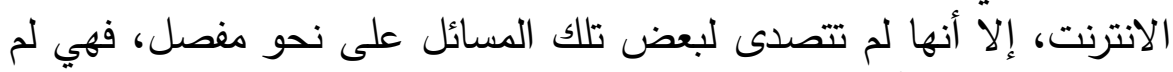

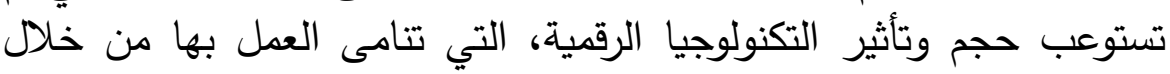


شبكة الانترنت، فهي لم تتعرض مثلا لفكرة التدابير التكنولوجية و المعلومات الضرورية لإدارة الحقوق.

فظهرت بعد ذلك معاهدة الويبو بثأن الأداء و التسجيل الصوتي لعام

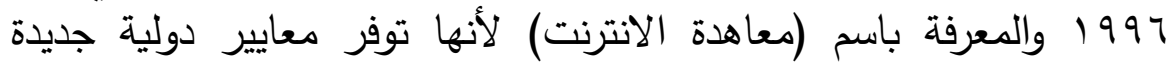

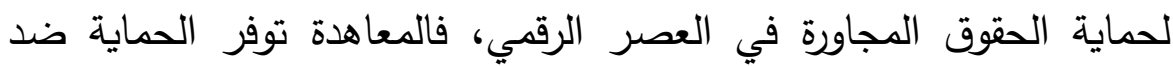

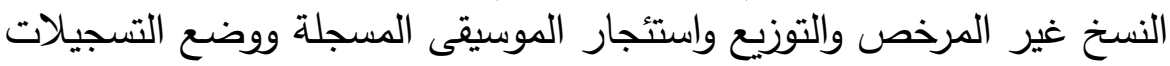
الصوتية المتاحة لهم على شبكات الانترنت، و ذلك باستخدام التدابير التثنية

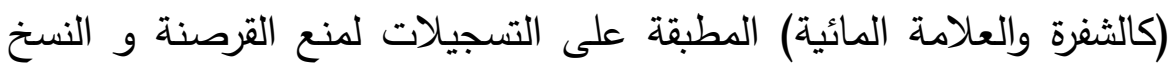

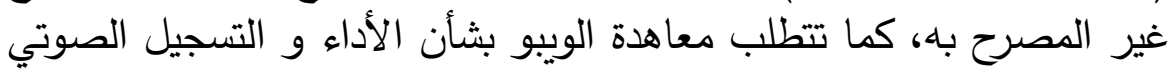

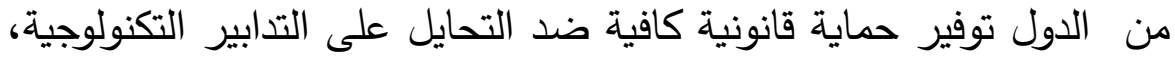

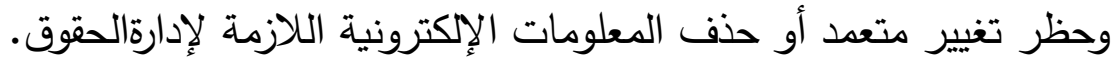

وهذه الحماية لها أهمية لأنشطة أصحاب المصلحة فيما يتعلق

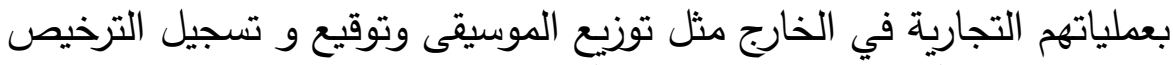

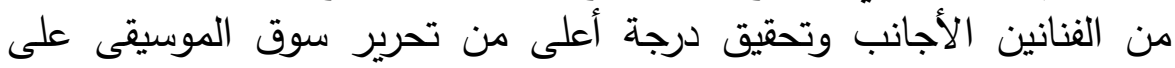

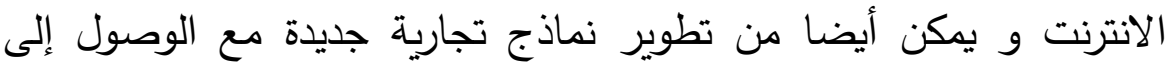

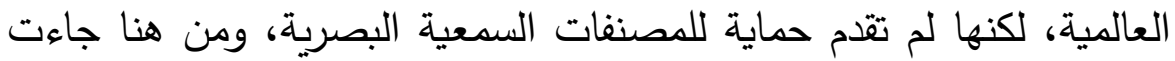

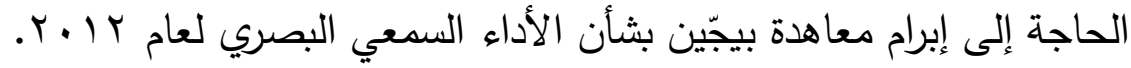

تحمي معاهدة بيجّين أوجه أداء الفنانين و المالكين لتلك الحقوق في

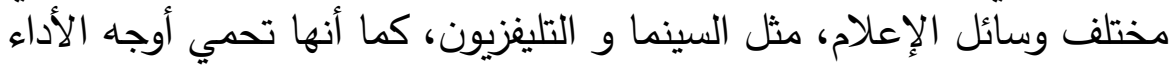

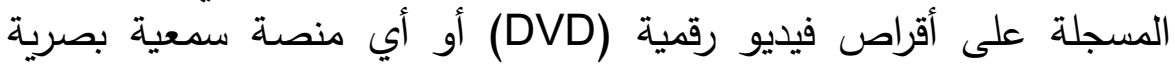

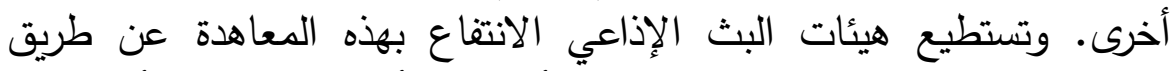

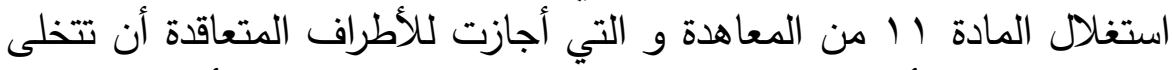

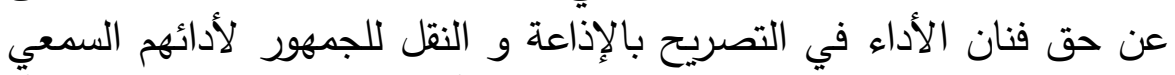

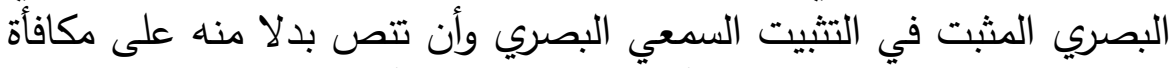

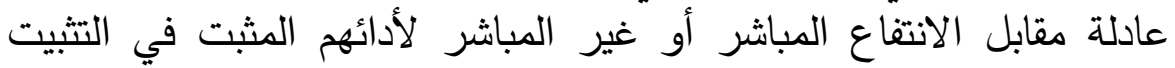
السمعي البصري لإذاعته أو نقله للجمهور .

وبذلك تضمن معاهدة بيجّين حصول هيئات البث الإذاعي على مكافآت

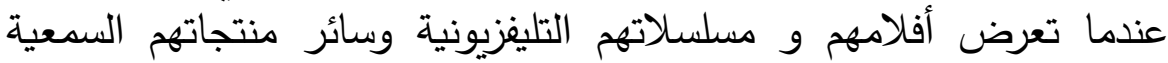
البصرية أو تتاح بأي شكل آخر في الخارج. أي أن المعاهدة تلعب دورائ في 
حماية المصنفات السمعية البصرية خاصة في هذه الحقبة الأخيرة التي يتزايد

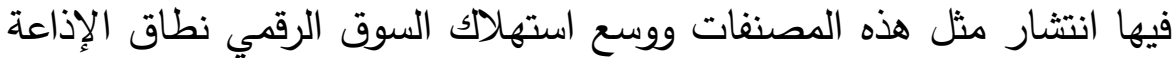

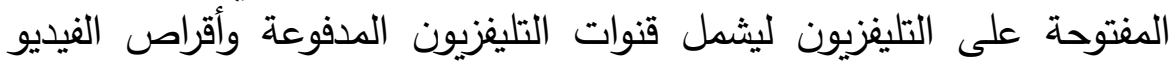

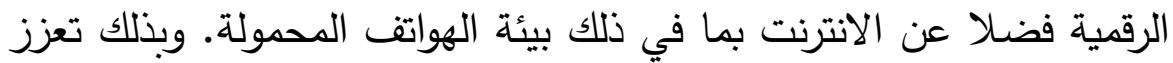

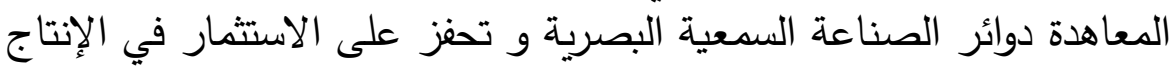

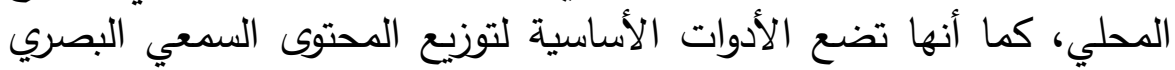
توزيعا متوازنا و آمنا و فعالا على الانترنت الادوات الاستية

أما بالنسبة لقانون حماية حقوق الملكية الفكربة المصري رقم ب ب لسنة

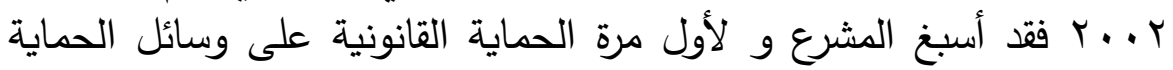

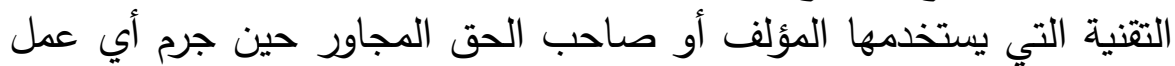

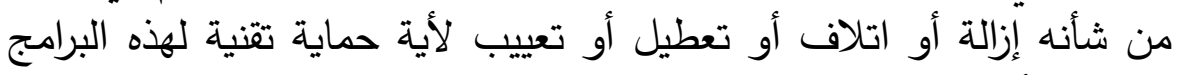
كالتشفير أو غيره.

كما أكد المشرع المصري على حماية تلك التدابير بشأن تقنيات برامج

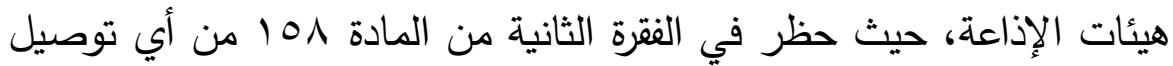

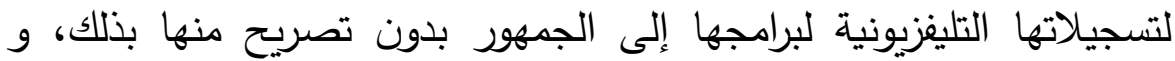
اعتبر من قبيل الأعمال المحظورة، الإزالة أو التعطيل أو الاتلاف لألية لهاتية حماية

تقنية لهذه البرامج كالتثفير وغيره.

لكن يؤخذ على هذا القانون أنه أعطى المنتج حق الاستغلال التجاري

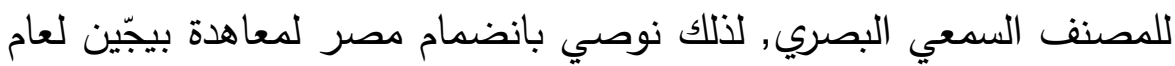

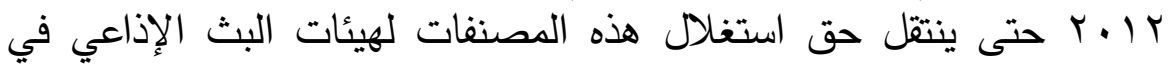

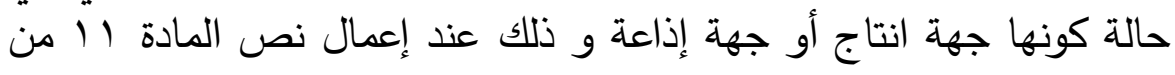
المعاهدة مما يترتب عليه الثراء الاقتصادي و الثقافي لهيئات البث الإذاعي.

ويلاحظ بالرغم من وجود معاهدات دولية تناولت الحماية في البيئة

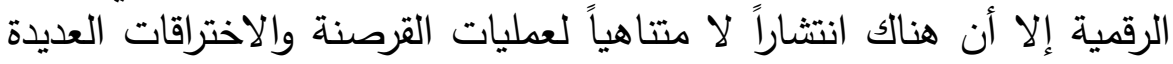

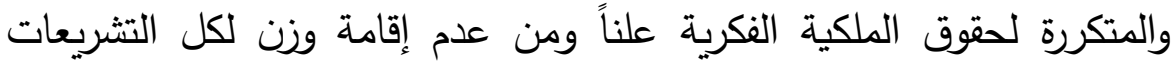

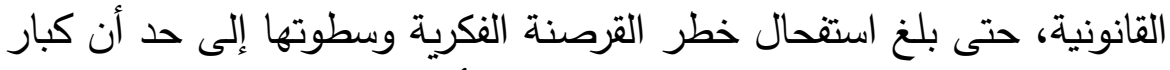

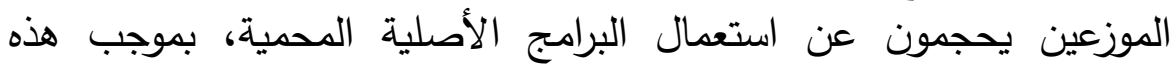

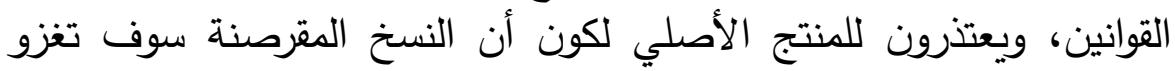
السوق حتى وقبل أن يفرغ المنتج الأصلي من ترتيب حمايته الإلكترونية 
القانونية أو التقنية. لذلك فإنه لا يكفي هنا سن النصوص القانونية أو تعديلها

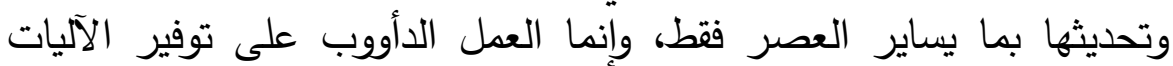

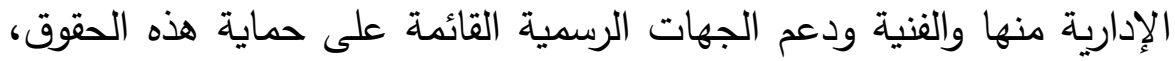

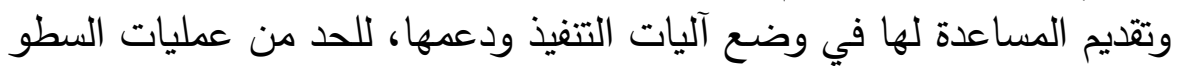

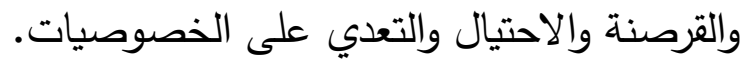

كما نوصي بضرورة إدراك أهل الاختصاص في مجال التقنية إلى إلى

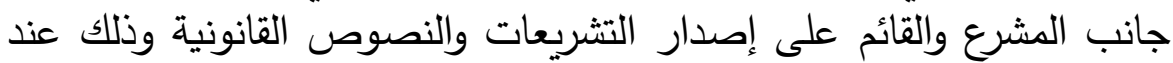

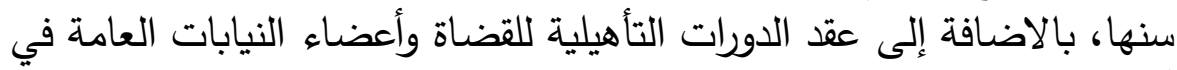

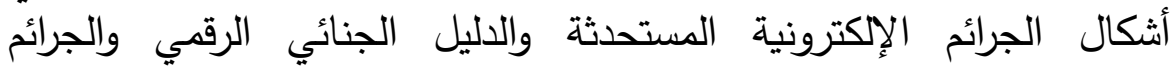

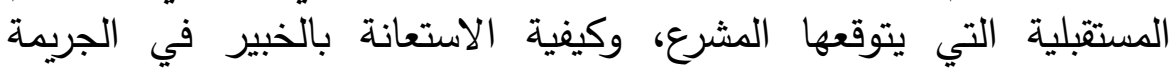

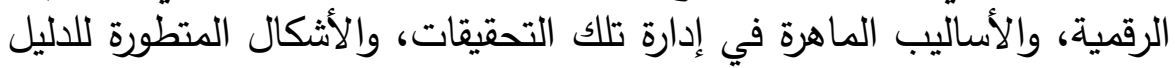
الجنائي 


\section{قائمة المراجع}

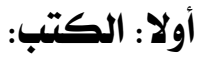

بدر، أحمد أنور (Y Y (Y). حقوق الملكية الفكرية و الرقابة

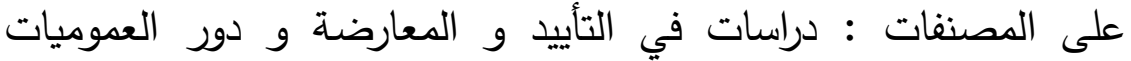

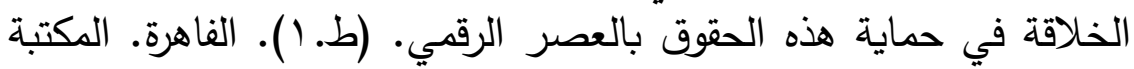
الأكاديمية.

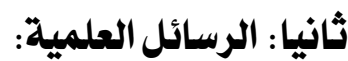

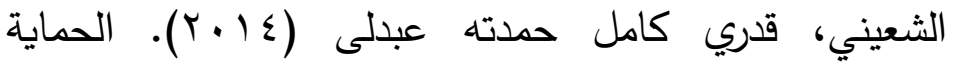

الجنائية للملكية الفكرية : دراسة مقارنة. أطروحة (دكتوراه) في الحقوق.

كلية الحقوق. جامعة القاهرة.

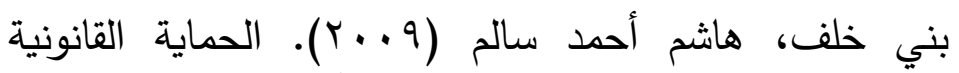

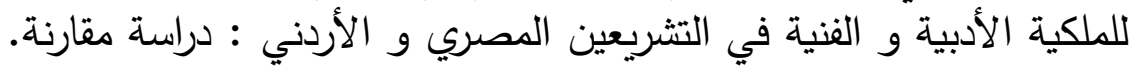

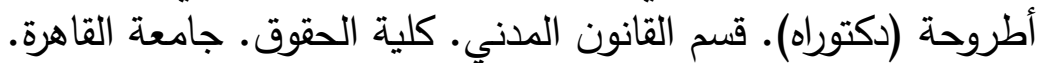

عجاج، وجدي محمد البيلي (ع ا • ب). الحماية القانونية الدولية للمصنفات الأدبية و الفنية. أطروحة (دكتوراه) في القانون. كلية الحقوق. جامعة القاهرة.

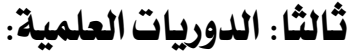

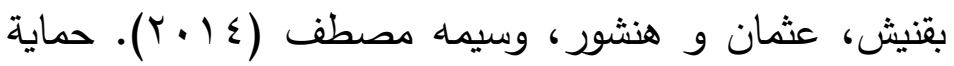
الملكية الفكرية عبر الانترنت في إطار المنظمة وان العالمية للملكية الفكرية. (منشورات مجلة دفاتلر قانونية : سلسلة المارية

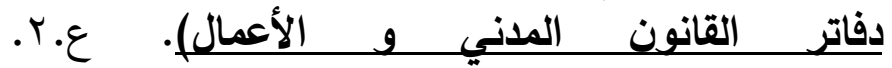
http://search.mandumah.com/Record/858105

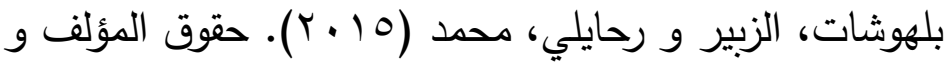
الحقوق المجاورة في البيئة الرقمية : الحالة الجزائرية. (مجلية

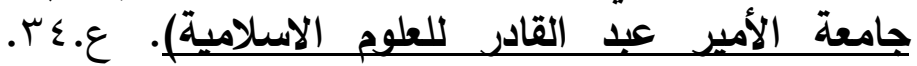
http://search.mandumah.com/Record/690569 


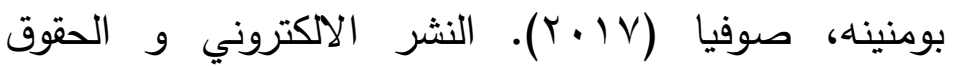

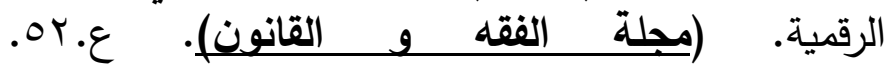
http://search.mandumah.com/Record/789724

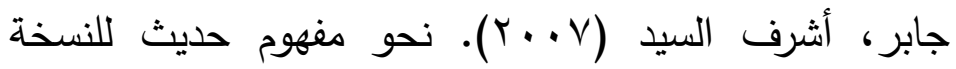
الخاصة : دراسة مقارنة في مفهوم النسخة الخاصة كأحد القيود

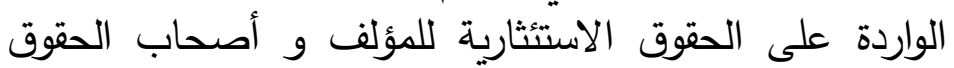

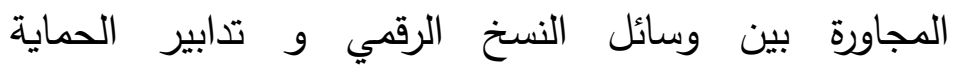

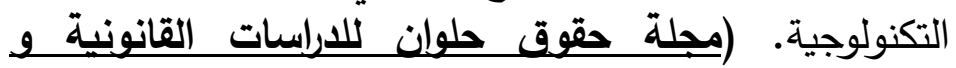
.IV.E

(الاقتصادية).

http://search.mandumah.com/Record/115507

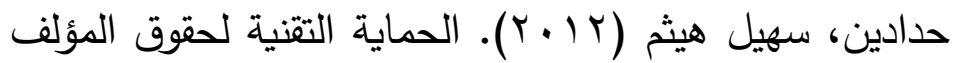

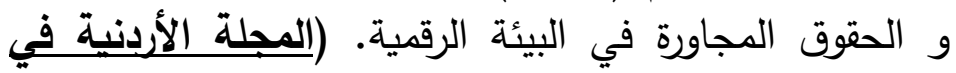

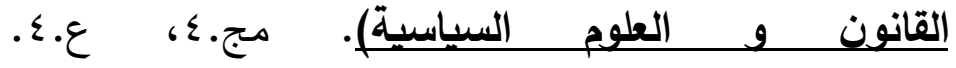
http://search.mandumah.com/Record/356605

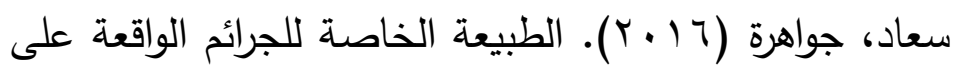

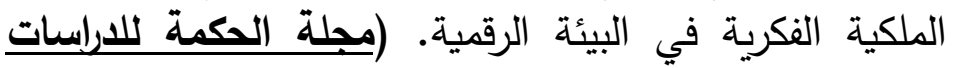
.^.ع (الاتصالية). 9

الاعلامية

http://search.mandumah.com/Record/769999

طه، أماني فوزي أحمد (ع ا ـ ب). الآثار الاقتصادية للتعدي

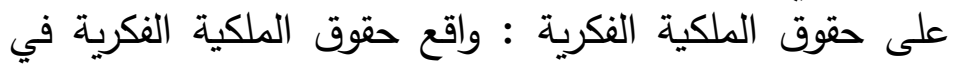

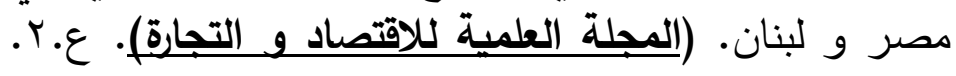
http://search.mandumah.com/Record/520171

عبد الفتاح، أميرة عبد الفتاح محمد (1) (1). تكنولوجيا الاتصال و الاعلام الاكتروني. (أعمال مؤتمرات : الاعلام (الاكتروني). http://search.mandumah.com/Record/120805 
رابعا: التشريعات و القوانين:

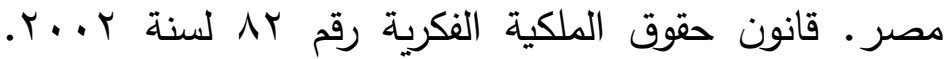

http://www.du.edu.eg/upFilesCenter/qaap/1388160304.

- pdf

\section{الاتفاقيات و المعاهدات الدولية:}

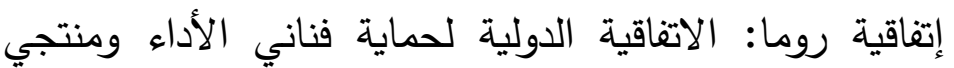

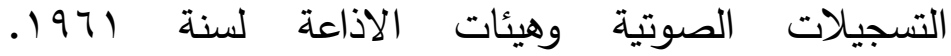

http://search.mandumah.com/Record/37639

• اتفاقية التربس : اتفاقية الجوانب المتصلة بالتجارة من حقوق

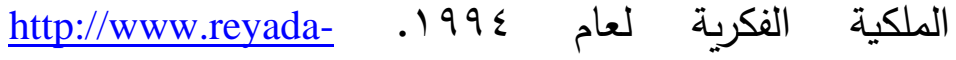

ip.com/uploads/3/4/9/1/34917865/tripsarabic.pdf

معاهدة الويبو بثأن الأداء و التسجيل الصوتي. كما تم

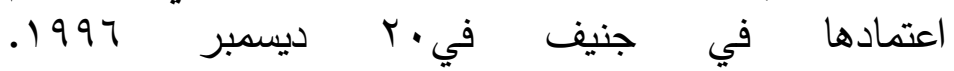

https://wipolex.wipo.int/ar/text/295476

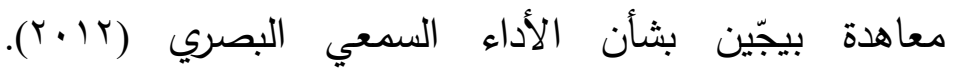

https://wipolex.wipo.int/ar/text/295836 